\title{
Kriegsmoral und Konfession. Perspektiven auf die katholische Feldpastoral Österreich-Ungarns im Ersten Weltkrieg im internationalen Kontext
}

\author{
Thomas Schulte-Umberg
}

\begin{abstract}
Within the framework of a moral theory of warfare, religion per se may well have a war morale promoting function in wars. Whether and to what extent this was the case in a given war can, of course, only be said on a case-by-case basis. A case report is presented here for the pastoral care of Austro-Hungarian troops during the First World War. In order to be able to identify both the specific and the general of the individual case, the field pastoral of other belligerent powers of the Great War is also taken into account. In comparison, the number of the Austro-Hungarian field chaplains was not as exceptional as is often assumed. Likewise the role of religion as a medium to embolden and reassure soldiers was shared in different belligerent nations. What mattered for the efficiency of pastoral care in war was that Austro-Hungarian leaders, a great number of their officers, and the troops believed in the ability of the chaplains to motivate the troops. However, this depended to a high degree on the consolatory and even dissociating aspects of catholic faith and practice.
\end{abstract}

World War I; Austro-Hungaria; pastoral care; field chaplains; religion; war morale; catholic faith and practice; international context; registration of war dead

Thomas Schulte-Umberg is University Assistant (post-Doc) at the Institute for Historic Theology, Faculty of Catholic Theology, University of Vienna. Currently he is finishing his book on War Morale and Religion. War experiences in the field pastoral of AustriaHungary and Germany in WW I. He is a member of the Research Platform "Religion and Transformation in Contemporary Society". Recent publications: with Angela Kallhoff, The Committed Soldier: Religion as a Necessary Supplement to a Moral Theory of Warfare, in: Politics, Religion \& Ideology 16 (2015) S. 434-448; with Angela Kallhoff, Die Wende zum Soldaten und Fragen der Kriegsmoral, in: DZPhil 65 (2017) S. 762-780; forthcoming, Religion im Ersten Weltkrieg. Ein Literaturbericht, to be published in: $\operatorname{ThRv} 114$ (2018)

\section{I. ,Durchhalten!"6}

Zwei römisch-katholische österreichisch-ungarische Feldkuraten (Militärgeistliche) des Ersten Weltkriegs haben es zu einigem literarischen Ruhm gebracht, Anton Allmer und Otto Katz. Karl Kraus hat Allmer in seine grandiose Kollage „Die letzten Tage der Menschheit“ einbezogen. In zwei kurzen, aufeinander 
folgenden Szenen besucht der Feldkurat, leutselig im Idiom der Heimat parlierend, zu deren Ermutigung die Mannschaft in den Stellungen und feuert dort fast spielerisch ein Gewehr bzw. ein Geschütz auf den Feind ab. ${ }^{1}$ Während es einen Feldkuraten Anton Allmer gab, ist Otto Katz eine in Jaroslav Hašeks Roman "Die Abenteuer des guten Soldaten Švejk“ ausführlich entwickelte Kunstfigur. Katz, dem Švejk einige Zeit als Offiziersdiener zur Verfügung steht, ist das Negativbild eines k.u.k. Feldkuraten. Der Umgang mit seinen pastoralen Pflichten wäre wohl als lästerlich zu bezeichnen, er säuft, frisst und ist den Damen sehr zugetan. Giovanni Boccaccios „Decamerone“ liegt im Krieg auf seinem Nachttisch, vor der „Priesterweihe betrank er sich fast bis zur Bewusstlosigkeit in einem sehr anständigen Hause mit Damenbedienung ... und ging dann in einem Taumel von Wollust und Vergnügen geradewegs los, um seine Weihen zu empfangen.“2

Auf einer bildkünstlerischen Ebene ist das Wirken der Geistlichkeit des Deutschen Reichs im Krieg in einigen in den 1920er Jahren gefertigten Zeichnungen George Grosz' verewigt worden. ${ }^{3}$ Eine zeigt einen Prediger auf der Kanzel, aus dessen Mund Kriegsgerät heraus gespien wird. In einer anderen ist Christus am Kreuz mit Gasmaske zu sehen, die Bildunterschrift lautet: „Maul halten und weiter dienen“. In einem Verfahren gegen ihn nach dem ,Gotteslästerungsparagraphen` ( $\$ 166$ StGB) argumentierte der Künstler, er habe lediglich die Kirche und deren Vertreter, soweit diese den Kriegsgeist gestützt hätten, kritisieren wollen. ${ }^{4}$ Mit „Durchhalten!“ hatte Grosz in einer weiteren Zeichnung

1 Vgl. Karl Kraus, Die letzten Tage der Menschheit. Tragödie in fünf Akten mit Vorspiel und Epilog, Frankfurt am Main 1986, S. 242-243. Als Vorlage diente „Feldkurat Allmer als Mitkämpfer“. Grazer Volksblatt Nr. 675, 12.12.1914, S.4. http://anno.onb.ac.at/cgi content/anno $?$ aid=gre \&datum $=19141212 \&$ query=\%22allmer\%22\&ref=anno-search. (Abruf: 10.10.2017) Während einiger Gedenkveranstaltungen in Österreich zum 100jährigen Beginn des Ersten Weltkriegs kam, wenn es um die Rolle von Kirchen und Geistlichkeit im Krieg ging, unweigerlich die Rede auf die von Kraus angeführten Allmer-Szenen.

2 Jaroslav Hašek, Die Abenteuer des guten Soldaten Šveyk im Weltkrieg, Stuttgart 2014, S. 101, zum „Decamerone“ S. 170, zu Katz als Figur S. 98-112, 128-196. Zu Šveyk und Katz in der tschechischen Kultur vgl. die Beobachtungen bei Tomáš Halik, Geduld mit Gott. Die Geschichte von Zachäus heute, Freiburg im Breisgau 2010, S. 101-102.

3 Vgl. George Grosz, Hintergrund. 17 Zeichnungen zur Aufführung des ,Schwejk“ in der Piscator-Bühne, Berlin 1928. Die vergrößerten Zeichnungen dienten als Bühnenhintergrund einer Berliner Theaterinszenierung von Hašeks Roman. Die Bildunterschrift zitiert einen Ausspruch Šveyks, vgl. Hašek, Abenteuer Šveyk, S. 23.

4 Vgl. Rosa Neugebauer, „George Grosz und sein Verhältnis zu Militarismus und Krieg“, in: Dietrich Harth (Hrsg.), Pazifismus zwischen den Weltkriegen: Deutsche Schriftsteller und Künstler gegen Krieg und Militarismus, 1918-1933, Heidelberg 1985, S. 147-164. Zur katholischen Kirche im Deutschen Reich vgl. Martin Lätzel, Die Katholische Kirche im Ersten Weltkrieg: Zwischen Nationalismus und Friedenswillen, Regensburg 2014. Neue Beiträge zur oftmals in diesem Zusammenhang angeführten 
eine zynische Permutation des Kriegsgeistes benannt. ${ }^{5}$ Irgendwo in einer Stadt des Hinterlandes schreit das Elend zweier Kriegsinvalider den überfressenen Zivilisten - und den Bildbetrachtern - ins Gesicht. Gegenüber den Grosz'schen Darstellungen wirken die beiden habsburgischen Kuraten wie eine Verkörperung der ausgehenden Monarchie, brutal gemütlich, dennoch humaner als die eiskalte, effektivere Kriegsmaschinerie des Deutschen Reichs. Und die Unterschiede zwischen den verbündeten Mächten sind unübersehbar.

Doch übergreifend standen der Kriegsalltag Österreich-Ungarns wie jener des Deutschen Reichs unter der Parole des „Durchhaltens“, naturgemäß je mehr, je länger dieser Krieg dauerte. ${ }^{6}$ „Durchhalten“ ist allerdings nur ein Wort für eine Sekundärtugend, die, wenn sie von Dauer sein soll, durch ein primäres Wertsystem einen tragfähigen Grund erhalten muss. ${ }^{7}$ Angesichts der bis dato nicht gekannten Intensität des „Großen Krieges“ von Anbeginn und seiner nichtsdestotrotz mehr als vierjährigen Dauer wird daher seit dem Krieg selbst gefragt, wie kognitive und emotionale Bindungen geformt und aufrecht erhalten werden konnten, welche das „Durchhalten“ von Kombattanten als eine sinnvolle Aufgabe mit insgesamt ungemein hohem Verpflichtungsgrad erscheinen ließen. Für diesen Zusammenhang hat sich mit Variationen die Bezeichnung Kriegsmoral eingebürgert. ${ }^{8}$ Sie bezeichnet den Grad der Bereitschaft von Truppenteilen und

Kriegspredigt in verschiedenen kriegführenden Nationen finden sich in Matthieu Arnold/ Irene Dingel (Hrsg.), Predigt im Ersten Weltkrieg. La prédication durant la "Grande Guerre" (= Veröffentlichungen des Instituts für Europäische Geschichte, Bd. 109), Göttingen 2017. Für die Kirchen im Deutschen Reich, Frankreich und Großbritannien vgl. auch Alan Kramer, Dynamic of Destruction. Culture and Mass Killing in the First World War, Oxford 2007, S. 175-180. Konzentriert auf die Nachkriegszeit vgl. Carsten Kretschmann, ,,Der Herr sei mit Euch, Ihr braven Krieger‘. Sakralisierungsstrategien im Kontext des Ersten Weltkriegs“, in: Karl-Joseph Hummel / Christoph Kösters (Hrsg.), Kirche, Krieg und Katholiken. Geschichte und Gedächtnis im 20. Jahrhundert, Freiburg / Basel / Wien 2014, S. 50-66.

5 Diese Zeichnung Grosz' findet sich in Magnus Hirschfeld, Sittengeschichte des Weltkriegs, Wien 1930, S. 29.

6 Für das Deutsche Reich und Österreich-Ungarn vgl. Alexander Watson, Ring of Steel: Germany and Austria-Hungary in World War I, New York, 2014; als international vergleichender Überblick Arnd Bauerkämper / Elise Julien (Hrsg.), Durchhalten! Krieg und Gesellschaft im Vergleich 1914-1918, Göttingen 2010; für die Bedeutung im Kriegsalltag einer Stadt Maureen Healy, Vienna and the Fall of the Habsburg Empire: Total War and Everyday Life in World War I, Cambridge 2007.

7 Für diesen Zugang sehr anregend u. a. Jana Osterkamp / Martin Schulze Wessel, „Texturen von Loyalität. Überlegungen zu einem analytischen Begriff“, in: GG 42 (2016) S. 553-573.

8 Vgl. Alexander Watson, „Morale“, in: Jay Winter and Editorial Committee of the International Research Centre of the Historial de la Grande Guerre (Hrsg.), The Cambridge History of the First World War, Vol. 2: The State, Cambridge 2014, S. 174-195. 
den Soldaten, aus denen diese bestehen, einen Krieg zu führen. Eine Vielfalt von Faktoren kann diese Bereitschaft beeinflussen, von denen nicht alle konstant wirksam oder gleich wichtig sind. Dazu zählen dürften auf jeden Fall der Glaube an eine Sache, Zuversicht auf einen Sieg, gute Ausbildung, Vertrauen in die militärischen Vorgesetzten, angemessener Nachschub und Loyalität zu den eigenen Kameraden.

Wie an anderer Stelle argumentiert, kann im Rahmen einer moralischen Theorie von Krieg Religion per se durchaus eine Kriegsmoral fördernde Funktion in Kriegen haben. ${ }^{9} \mathrm{Ob}$ und in welchem Ausma $\beta$ dies in einem bestimmten Krieg so war, lässt sich freilich nur fallweise sagen. Eine Falldarstellung wird im Folgenden für die katholische Feldpastoral (Militärseelsorge) Österreich-Ungarns im Ersten Weltkrieg vorgelegt. Abgesehen von der hier notwendigen Begrenzung und Zuspitzung ist eine solche nur sinnvoll, wenn ihr erstens eine „dichte Beschreibung“ (Clifford Geertz) zugrunde liegt. Für diese bieten insbesondere die ,gewaltigen Bestände“10 des Wiener Kriegsarchivs eine mehr als hinreichende Grundlage, die für das Thema erstmalig umfassender erschlossen wurden. ${ }^{11} \mathrm{Um}$ sowohl das spezifische wie das allgemeine des Einzelfalles benennen zu können, war zweitens ansatzweise die Feldpastoral anderer kriegführender Mächte des ,Großen Krieges‘ mit zu berücksichtigen. ${ }^{12}$ Die Frage nach Religion im Krieg

9 Vgl. Angela Kallhoff / Thomas Schulte-Umberg, ,The Committed Soldier: Religion as a Necessary Supplement to a Moral Theory of Warfare“, in: Politics, Religion \& Ideology 16 (2015) S. 434-448; dies., „Die Wende zum Soldaten und Fragen der Kriegsmoral“, in: DZPhil 65 (2017) S. 762-780 sowie Ron E. Hassner, Religion on the Battlefield, Ithaca 2016.

10 Michael Hochedlinger, „Kleine Quellenkunde zur österreichischen Militärgeschichte 1800-1914“, in: Laurence Cole / Christa Hämmerle / Martin Scheutz (Hrsg.), Glanz-Gewalt-Gehorsam: Militär und Gesellschaft in der Habsburgermonarchie (1800 bis 1918) (= Frieden und Krieg. Beiträge zur historischen Friedensforschung, Bd. 18), Essen 2011, S. 387-410, S. 402.

11 Eine umfassende Auswertung erfolgt in meiner im Abschluss befindlichen Studie Kriegsmoral und Religion. Kriegserfahrungen in der katholischen Feldpastoral ÖsterreichUngarns und des Deutschen Reichs im Ersten Weltkrieg.

12 Als Versuch einer vergleichenden, die Feldpastoral des Deutschen Reichs und Österreich-Ungarns aber unberücksichtigt lassenden Darstellung vgl. Xavier Boniface, Histoire religieuse de la Grande Guerre, Paris 2014, S. 61-112. Für die Feldpastoral der beiden genannten Staaten vgl. Patrick J. Houlihan, Catholicism and the Great War: Religion and Everyday Life in Germany and Austria-Hungary, 1914-1922, Cambridge 2015, S. 78-116. Die von Houlihan präsentierten Ergebnisse beruhen auf seiner Dissertation Clergy in the Trenches. Catholic Military Chaplains of Austria-Hungary and Germany in the First World War, Phil. Diss., Chicago 2011. Wie andernorts ausführlich gezeigt, war insbesondere die Auswertung des Quellenmaterials im Wiener Österreichischen Staatsarchiv (=OeSta), Abteilung Kriegsarchiv (=KA) wenig in die Tiefe gehend und trug mit dazu bei, dass - neben etlichen argumentativen Schwächen - zahlreiche Fehler 
Thomas Schulte-Umberg

bedingt allemal die „Notwendigkeit eines komparatistischen Ansatzes und fordert dazu auf, ihre Geschichte stärker im internationalen Kontext zu betrachten." 13

\section{Verstetigung}

Die Teilnahme an einem Krieg konfrontiert Kombattanten mit dem Potential, andere zu töten, und aus ihrer Sicht vor allem mit der Gefahr, selbst getötet zu werden. Im Zeitalter von Massenarmeen und Wehrpflicht war es nicht unbedingt anzunehmen, die Mehrzahl der Soldaten würde fähig und willens sein, dauerhaft ihren eigenen Tod in Kauf zu nehmen. ${ }^{14}$ Schon zeitgenössisch wurden Überlegungen angestellt, was dennoch die Gründe für die Bereitschaft von Soldaten waren, an diesem Krieg nicht nur mehr als vier Jahre teilzunehmen, sondern ein insgesamt hohes Maß an Durchhaltevermögen an den Tag zu legen. Einige Mannschaften, vor allem aber Offiziere hatten die passenden Worte dafür: Zahlen und Ausrüstung zählten, aber der entscheidende Faktor für den Ausgang des Krieges war der moralische Wert der Truppen. ${ }^{15}$

und Auslassungen zu verzeichnen sind, die zu einem schrägen Gesamtbild führen. Vgl. Thomas Schulte-Umberg, „Religion im Ersten Weltkrieg“, erscheint in: ThRv 114 (2018). Ähnlich vgl. bereits die Rezensionen von Catholicism and Great War u.a. von Rebekka Ayako Bennette, CEH 49 (2016) S. 276-277; Michael Egger, HZ 304 (2017) S. 258-259; Lauren Faulkner-Rossi, in: AHR 122 (2017) S. 947-948. Erste kursorische Einblicke in die evangelische und katholische Militärseelsorge in der Habsburgermonarchie bietet Claudia Ham, ,,Von den Anfängen der Militärseelsorge bis zur Liquidierung des Apostolischen Feldvikariates im Jahr 1918“, in: Roman-Hans Gröger / Claudia Ham / Alfred Sammer, Zwischen Himmel und Erde. Militärseelsorge in Österreich, Graz / Wien / Köln 2011, S. 13-98. Eine knappe globale Gesamtdarstellung zum Christentum im Krieg bietet Martin Greschat, Der Erste Weltkrieg und die Christenheit: Ein globaler Überblick, Stuttgart, 2013.

13 Lawrence Cole / Christa Hämmerle / Martin Scheutz, „Glanz - Gewalt - Gehorsam. Traditionen und Perspektiven der Militärgeschichtsschreibung zur Habsburgermonarchie“, in: dies. (Hrsg.), Glanz - Gewalt - Gehorsam: Militär und Gesellschaft in der Habsburgermonarchie (1800 bis 1918) (= Frieden und Krieg. Beiträge zur historischen Friedensforschung, Bd. 18), Essen 2011, S. 13-28, S. 18.

14 In der besten zeitgenössischen, auf Umfragematerial beruhenden Studie zu Einstellungen deutscher Weltkriegssoldaten wird darauf verwiesen, dass das Töten des Gegners in relativ banalen, auch rohen Worten beschrieben wird, ohne dem Akt des Tötens größere Bedeutung beizumessen. Vgl. Paul Plaut, „Psychographie des Kriegers“, in: Wilhelm Stern / Otto Lipmann (Hrsg.), Beihefte zur Zeitschrift für angewandte Psychologie, Bd. 20, Leipzig 1920, S. 1-123, S. 68-69. Allgemein vgl. John Keegan, The Face of Battle, New York, 1976, S. 297-298.

$15 \mathrm{Vgl}$. Ferdinand Foch, Des principes de la guerre. Conférences faites en 1900 à l'École 
Der österreichisch-ungarische Offizier Constantin Schneider notierte in seinen Kriegserinnerungen über den russischen Gegner:

Vom Feind: auch diese letzte Zeit rang er uns Achtung ab. Er handelte immer wie ein Mann. Seine Kriegslisten muß man ihm verzeihen, denn später sah man ein, daß das, was er uns gegenüber voraus hatte, einzig seine Kriegsmoral war. Auch sie ist Moral ... sie unterwirft sich rücksichtslos alle Mittel, die zum Siege führen. ${ }^{16}$

Solche Erfahrungen resümierend erklärte ein deutscher Veteran und Militärwissenschaftler in den frühen 1930er Jahren Ausrüstung, Nachschub, Training, Ruhezeiten, durch strenge Disziplin erzeugter Wille zum Gehorsam legten eine Basis für die Kriegsführung, diese sei aber nur auf Dauer erfolgreich, wenn es gelinge, dem einzelnen Soldaten seine „Berufspflichten ... zu einem wirklichen inneren Werterlebnis zu machen. "17 Anders als in früheren Kriegen war aus seiner Sicht für den einzelnen Soldaten äußere Folgsamkeit mit innerer, im Gewissen verpflichtender Einsicht unbedingt zu verbinden. Wie der Krieg zeigte, konnte dies unter Kampfbedingungen nur bei Existenz einer „cohésion morale“18 auf überschaubarer Gruppenebene funktionieren. Die nach der Niederlage gegen Preußen-Deutschland 1870/71 formulierte Einsicht in die Bedeutung von ,Primärgruppen“ im Sinne selbständiger, sich selbst gewissermaßen anleitender Teams von wenigen Dutzend Soldaten, die heute eine Selbstverständlichkeit für professionelle Armeen ist, bildete sich im Ersten Weltkrieg erst nach und nach aus, war aber praktisch für das Durchhaltevermögen von Soldaten auf den Schlachtfeldern mit entscheidend. ${ }^{19}$

supérieure de guerre, Paris 1911, S. 270; Franz Conrad von Hötzendorf, Aus meiner Dienstzeit. 1906-1918, Bd. 4, Wien 1923, S. 222 sowie eine bei Watson, Ring of Steel, S. 108 zitierte Äußerung des deutschen Generalstabschefs Moltke. In Kriegstagebüchern von Soldaten finden sich gelegentlich Wendungen, die ebenfalls in diese Richtung weisen.

16 Constantin Schneider, Die Kriegserinnerungen.1914-1919, hg. von Oskar Dohle (=Veröffentlichungen der Kommission für Neuere Geschichte Österreichs, Bd. 95), Wien 2003, S. 353.

17 Friedrich Altrichter, Die seelischen Kräfte des deutschen Heeres im Frieden und im Weltkriege, Berlin 1933, S. 31.

18 Charles Ardant le Picq, Études sur le Combat, Paris 1880, S. 84, zum Zusammenhang S. 75-87.

19 Vgl. Anthony King, The Combat Soldier: Infantry Tactics and Cohesion in the Twentieth and Twenty-First Centuries, Oxford 2013. Die im Deutschen Reich und in Österreich-Ungarn in Vorkriegszeiten praktizierte regionale Rekrutierung von Truppenteilen kam dem zugute. Sie konnte jedoch im Krieg nicht im Vorkriegsausmaß aufrechterhalten werden. Vgl. Christian Stachelbeck, Deutschlands Heer und Marine im Ersten Weltkrieg, Paderborn u.a. 2013, S. 166-167; Günter Kronenbitter, „Krieg im 
Thomas Schulte-Umberg

Militärische Organisation allein konnte insgesamt keine auf Dauer tragfähige Basis für die Moral von Millionen Kombattanten sein. In diesem Sinn ist es auch zu verstehen, wenn - manches Mal wider besseres Wissen - der Ruf zu den Waffen in allen kriegführenden Ländern als ein gerechter Krieg bzw. als Defensivkrieg zur Verteidigung der Heimat bezeichnet wurde. ${ }^{20}$ Die Drohung einer Invasion, angebliche und tatsächliche Kriegsverbrechen des Feindes und das Wissen um die Verwüstung von Städten, Dörfern und Landschaften trugen in hohem Maße zur Verpflichtung auf die Sache bei. Variationen von Aussagen wie: „Glücklicherweise ist unser Dorf bisher verschont geblieben“ oder: „Ich kämpfe für Dich/ Euch" können in vielen der Millionen Briefe gefunden werden, die zwischen Front und Heimat ausgetauscht wurden. ${ }^{21}$ Die Rückbindung an die Heimat hatte aber Grenzen. Das häufig anzutreffende Unverständnis von Zivilisten für die Realitäten des Krieges, Kriegsgewinnler, ein völlig begründetes Maß an Misstrauen gegenüber den organisatorischen Kompetenzen der Regierungen, später eine Hungersnot im Deutschen Reich, Österreich-Ungarn und dem Zarenreich sowie die länger als erwartete Dauer des Krieges fochten früher oder später die soldatische Moral an. ${ }^{22}$

Höhere militärische Führer wandten sich zwecks deren Hebung Religion und deren Repräsentanten auf dem Schlachtfeld, den Militärgeistlichen zu. Dem katholischen Divisionspfarrer einer bayerischen Infanteriedivision wurde im November 1915 vom Kommandeur erklärt,

daß der Schützengrabenkrieg neue Anforderungen an die Mannschaften und neue an die Geistlichen stelle. Exc.[ellenz] wünscht, daß in den Predigten betont werde, daß die Opfer für das Vaterland von seiten der Krieger verdienstlich für den Himmel seien. ... Man habe früher nicht geahnt, daß die Seelsorge im Stellungskrieg wie jetzt von so tiefeinschneidender Bedeutung sei. ${ }^{23}$

Frieden“. Die Führung der k.u.k. Armee und Österreich-Ungarns Großmachtpolitik 19061914, München 2003, S. 13.

20 Auf die Lehre vom gerechten Krieg und dessen Propagierung durch die Kirchen sei hier nur verwiesen. Als historischen Überblick zu den Ausprägungen der Lehre vgl. Alex J. Bellamy, Just wars: from Cicero to Iraq, Cambridge / Malden 2006. Zur Auslegung vgl. Lätzel, Kirche im Ersten Weltkrieg, S. 62-66; Wilhelm Achleitner, Gott im Krieg. Die Theologie der österreichischen Bischöfe in den Hirtenbriefen zum Ersten Weltkrieg, WienKöln-Weimar 1997, S. 262-269.

21 Vgl. Watson, Ring of Steel, S. 288; am bayrischen Beispiel Benjamin Ziemann, Front und Heimat: ländliche Kriegserfahrungen im südlichen Bayern 1914-1923 (= Veröffentlichungen des Instituts zur Erforschung der europäischen Arbeiterbewegung, Bd. 8), Essen 1997, S. 77-97; allgemein Cramer, Dynamic of Destruction, S. 244.

22 Vgl. Watson, Morale, S. 191.

23 Carl Werner Müller (Hrsg.), ,Verzicht auf Revanche“: Das Kriegstagebuch 1914/18 des Divisionspfarrers der Landauer Garnison Dr. Anton Foohs (= Veröffentlichungen 
Der Kommandeur der britischen Truppen an der Westfront, seit Dezember 1915 General Douglas Haig, wandte diesen Gedanken auf den Offensivkrieg an. In Vorbereitung der Somme-Offensive forcierte er die bis dahin eher zurückhaltend und dysfunktional ausgeübte Pastorierung der britischen Truppen. ${ }^{24}$ Entscheidend schien auch ihm der Beitrag, den die Geistlichen zur Hebung der Moral leisten könnten. Ihr Einsatzraum wurde so definiert, dass der Aufenthalt in den Schützengräben auch bei größeren Kampfhandlungen möglich war. Kurz vor Beginn der Offensive schrieb er in einem Brief an den englischen König, die eigenen Truppen seien noch nie so guten Geistes gewesen, und dafür seien die Militärgeistlichen zu einem großen Teil verantwortlich. ${ }^{25}$

\section{Militärseelsorgen}

Die Zuwendung zur Religion als einem Verstärker für die Moral der Truppe war im frühen 20. Jahrhundert in Europa wenig erstaunlich. Für die Generation, die im Ersten Weltkrieg kämpfte, waren religiöser Glaube und religiöse Praxis eher der Normalfall. ${ }^{26}$ Alle kriegführenden Mächte in Europa rekurrierten in hohem $\mathrm{Maß}$ auf die Dienste der Kirchen und religiösen Gemeinschaften. Nichts verdeutlicht dies besser als die massive Expansion oder überhaupt die Schaffung von Militärseelsorgen. Im laizistischen Frankreich und im Königreich Italien, Ländern mit überwiegend katholischer Bevölkerung, deren Regierungen sich im Konflikt mit Papsttum und katholischer Kirche befanden, wurden die Truppen von vielen Tausend Geistlichen begleitet. ${ }^{27}$ In Frankreich gab es nur 800 ,reguläre' Militärseelsorger. Entsprechend den französischen Wehrgesetzen konnten jedoch Priester zum Kriegsdienst herangezogen werden, die Gesamtzahl der eingezogenen Kleriker wird auf 22.000 bis 24.000 geschätzt. Von ihnen dienten $5 \%$ bis $10 \%$ freiwillig als Militärseelsorger, jedes französische Bataillon hatte rein rechnerisch seinen Priester. Ähnlich war die Situation in Italien, dort dienten etwa 15.000 Geistliche, 2.400 von ihnen als Militärseelsorger. In am Krieg auf alliierter Seite beteiligten weiteren Monarchien Europas waren Militärseelsorgen bereits

der Pfälzischen Gesellschaft zur Förderung der Wissenschaften, Bd. 108), Speyer 2010, S. 100 Eintrag vom 16.11.1915.

24 Vgl. Michael Snape, God and the British Soldier: Religion and the British Army in the First and Second World Wars, London / New York, 2005, S. 92-102.

25 Vgl. ebd., S. 99.

26 Vgl. Michael Snape, „The Great War“, in: Hugh McLeod (Hrsg.), The Cambridge History of Christianity Vol. 9: World Christianities c. 1914-c. 2000, Cambridge 2006, S. 131-150, S. 139.

27 Vgl. Xavier Boniface, L'aumônerie militaire française, 1914-1962, Paris 2001, S. 65153, zu den Zahlen S. 81-83; Roberto Morozzo Della Rocca, La fede e la guerra. Cappellani militari e preti soldati 1915-1919, Udine 2015, S. 14-16. 
vorhanden, die im Krieg ausgebaut wurden. In der belgischen Armee hatte alsbald nach einer Initiative des Königs jedes Bataillon einen Feldgeistlichen. ${ }^{28}$ Die Zahl der Militärgeistlichen in der Zarenarmee war demgegenüber, obwohl die orthodoxe Geistlichkeit zweifellos eine Stütze des Zarismus war, vergleichsweise weniger hoch, ihre Zahl wird für 1915 mit 2.000 bis 2.500 angegeben. ${ }^{29}$

Die Militärseelsorgen des Ersten Weltkriegs unterschieden sich je nach Nation in ihren Organisationsformen und Praktiken. So spielte die konfessionelle $\mathrm{Zu}$ sammensetzung eine bedeutende Rolle, es gab bemerkenswerterweise ebenso die Akzeptanz wie Überbrückung religiöser Differenz. Als US-Truppen 1917 auf den Schlachtfeldern Westeuropas eintrafen, wurden sie von mehrheitlich freiwilligen Militärgeistlichen begleitet, die als einheitliche ,Schar von Brüdern' organisiert waren und unter Kriegsbedingungen ein Zeichen der Einheit in einer multiethnischen Gesellschaft mit ihren konfessionellen Verwerfungen repräsentierten. ${ }^{30}$ Im deutschen Heer feierten katholische und protestantische Geistliche vor allem in den ersten Monaten des Krieges gelegentlich interkonfessionelle Gottesdienste und predigten öfter für Soldaten beider Konfessionen. ${ }^{31}$ In ÖsterreichUngarn dagegen wurde die Beachtung konfessioneller Grenzen betont. So wurde die Frage der unter Kriegsbedingungen eigentlich unabdingbaren Vereinheitlichung von Feiertagen der Kombattanten römisch-katholischen, griechisch-katholischen und griechisch-orientalischen Bekenntnisses recht behutsam angegangen, so wurden die Speisevorschriften von muslimischen Soldaten und muslimische Begräbnisvorschriften zu achten gesucht. ${ }^{32}$

28 Zur belgischen Militärseelsorge im Ersten Weltkrieg vgl. Jacques-Robert Leconte, L'Aumônerie Militaire Belge, Brüssel 1966, S. 8-21.

29 Vgl. Dietrich Beyrau, „Projektionen, Imaginationen und Visionen. Die orthodoxe Militärgeistlichkeit im Einsatz für Glauben, Zar und Vaterland 1914-1917“, in: JGO 52 (2004), S.402-420, S. 403.

30 Vgl. Timothy J. Demy, „Military Chaplains in the First World War“, in: Gordon L. Heath (Hrsg.), American Churches in the First World War, Eugene (OR) 2016, S. 95-102; Michael E. Shay, Sky Pilots: The Yankee Division Chaplains in World War I, Columbia 2014.

31 Vgl. Bericht über die Militär-Pfarrkonferenz der 2. Armee in St. Quentin, 17.5.1915. Bundesarchiv (= BA) Militärarchiv Freiburg im Breisgau (MA) PH 32, 390; Pater Adalbert Kraft, Pastoralbericht, 22.9.1917. BA MA PH 32, 131.

32 Vgl. die unter OeSta KA AFV (= Apostolisches Feldvikariat) Bücher Journal 1916, Nr. 37627 dokumentierten Verhandlungen zur Vereinheitlichung der Feiertage. Zu muslimischen Speisevorschriften vgl. Militär Imam *** [Name unlesbar] an Militärkommando Wien, Wien 29.6.1917. OeSta KA Generalkommando (= GKmdo) Wien Akten Militärabteilung (= MA) Karton (= Ktn.) 3135, 38-2-7-7, zu Begräbnisvorschriften Kriegsministerium $(=\mathrm{KM})$ Abt. 9 an Gemeinsames Finanzministerium in Angelegenheiten Bosnien-Herzegowina und an Militärkommando Budapest, Wien 7.11.1914 (Entwurf). OeSta KA KM Abt. 9 Akten 1914 Ktn. 467 11-9-2. - Griechischkatholisch ist eine Sammelbezeichnung für die Mitglieder der mit Rom unierten Ost- 
Für die Organisation der katholischen Militärseelsorgen des Ersten Weltkriegs wäre angesichts des zeitgenössischen Kirchenverständnisses ein hierarchischer Aufbau zu erwarten gewesen. In der Praxis bietet sich jedoch ein durchaus differenziertes Bild. Wie in Italien standen im Deutschen Reich und in ÖsterreichUngarn Bischöfe an der Spitze der katholischen Militärseelsorgen. ${ }^{33}$ Ihr Einfluss variierte allerdings stark. Der habsburgische Militärbischof Emmerich Bjelik hatte einen theoretisch wie praktisch durchgreifenden Einfluss, ${ }^{34}$ während der preußische Feldpropst Heinrich Joeppen wenig sichtbar war. ${ }^{35}$ Diese Differenz setzte sich bei den beiden Zentralmächten nach weiter unten hin fort. Während die Armeen der Habsburgermonarchie von Anbeginn eigene, dem Militärbischof unterstehende Feldsuperiore hatten, welche die in den Truppenformationen dienenden Geistlichen anleiten und beaufsichtigen sollten, wurden ähnliche Positionen im deutschen Heer erst nach und nach eingeführt, die mit schwächeren Weisungsrechten ausgestattet waren. ${ }^{36}$ Auf der Ebene der habsburgischen Divisionen und Brigaden gab es Seelsorgsleiter, die als Vorgesetzte der Geistlichen der ihrer militärischen Einheit zugeordneten Truppen fungierten. Den katholischen Divisionsgeistlichen der preußischen Armee waren dagegen die weiteren der Division zugehörigen Geistlichen nicht untergeordnet. ${ }^{37}$ In Frankreich wie-

kirchen byzantinischen Ritus auf dem Gebiet der Monarchie, die 1910 gut 10 \% der Gesamtbevölkerung stellten, griechisch-orientalisch für diejenigen der orthodoxen Kirchen (ca. 9 \%). Vgl. Rupert Klieber, jüdische - christliche-muslimische Lebenswelten der Donaumonarchie 1848-1918, Wien 2010, S. 285. Der griechisch-katholische Feldklerus unterstand Militärbischof Bjelik.

33 Die Organisation der deutschen Militärseelsorge im Ersten Weltkrieg ist im Überblick gut dargestellt bei Arnold Vogt, Religion im Militär. Seelsorge zwischen Kriegsverherrlichung und Humanität. Eine militärgeschichtliche Studie (= Europäische Hochschulschriften Reihe III, Bd. 253), Frankfurt am Main / Berlin / New York 1984, S. 479-524. Zum italienischen Militärbischof vgl. Della Rocca, La fede e la guerra, S. 26. 34 Präsent war der habsburgische Feldbischof u. a. durch seine zahlreichen Inspektionsreisen, vgl. bei Viktor Lipusch, Österreich-Ungarns katholische Militärseelsorge im Weltkriege, Wien 1938, S. 50-51 die Aufzählung der Reisen bis Spätsommer 1916.

35 Joeppen unternahm nur zwei Frontreisen. Vgl. Artikel „Joeppen“ in: Hans Jürgen Brandt / Peter Häger (Hrsg.), Biographisches Lexikon der Katholischen Militärseelsorge Deutschlands 1848-1945, Paderborn 2002, S. 369-371. Sein Verbleib in Berlin entsprach allerdings der Tradition der preußischen Feldpropstei. Die Aktivitäten des preußischen Militärbischofs Joeppen waren so beschränkt, dass sie wohlwollend als nur die Überwachung der Gottesdienstordnung und des Predigtamtes betreffend bezeichnet wurden. Vgl. Franz Albert, Handbuch für die katholischen Feldgeistlichen des preußischen Heeres, Wilna 1918, S. 30.

36 Vgl. Vogt, Religion im Militär, S. 492-504.

37 Vgl. Albert, Handbuch, S. 27. 
derum gab es keinerlei hierarchischen Aufbau, mit der Folge, dass jeder sein Amt so ausübte, wie er es für richtig erachtete. ${ }^{38}$

Trotz dieser Differenzen wurde die Funktion der Militärseelsorge allenthalben ähnlich gesehen. Beispielhaft ist die Begründung für die Etablierung der italienischen Militärseelsorge. Kurz vor dem Kriegseintritt Italiens 1915 wies der Oberkommandierende General Luigi Cadorna jedem Regiment einen Militärgeistlichen zu. Eine Absicht war es, die Meinung der italienischen Katholiken für den Kriegseintritt zu beeinflussen. Aber noch mehr ging es darum, „l'attività dei cappellani in quanto fattore di coesione morale sulla commune base religiosa, e di spirito di disciplina fra le truppe " zu nutzen. ${ }^{39}$ Antonio Gramsci hatte völlig recht, wenn er Jahrzehnte später die Funktion der Militärgeistlichen als die von ,Moralvervielfältigern' beschrieb. ${ }^{40}$

\section{Sprachen}

Die Bedeutung von Religion und Konfession in der ausgehenden Habsburgermonarchie als einer der Säulen des Reichs neben Bürokratie und Armee ist unbestritten. ${ }^{41}$ Das bildete sich im quantitativen Umfang der Militärseelsorge ab. Insgesamt dienten im Verlauf des Krieges mehr als 3.000 römisch-katholische Feldkuraten in den habsburgischen Streitkräften. ${ }^{42}$ Jedes Regiment sollte seinen eigenen Kuraten haben, eine Division hatte im Schnitt etwa 16 Militärgeistliche aller Konfessionen. ${ }^{43}$ Mit eigenen Feldkuraten versehen sein sollten weiterhin die meisten Sanitätsanstalten, die Kriegsgefangenenlager und weitere Standorte in Etappe und Hinterland. Besonders bei den in der Alpenregion eingesetzten Truppen gab es Bataillonsseelsorgen. ${ }^{44}$ Im Gegensatz zu Frankreich und Italien

\footnotetext{
38 Vgl. Boniface, L'aumônerie, S. 79.

39 Della Rocca, La fede e la guerra, S. 12.

40 Vgl. Antonio Gramsci, Passato e Presente (= Opero di Antonio Gramsci, 7), Mailand 1954, S. 43.
}

41 Vgl. Klieber, Lebenswelten, S. 101-102.

42 Die bei Lipusch, Militärseelsorge, S. 99 genannte Zahl von 3.000 Feldkuraten dürfte nach den Angaben in den Beständen des Kriegsministeriums und des Apostolischen Feldvikars im OeSta KA zu niedrig sein. Die oben genannten, von Lipusch übernommenen Angaben müssen als Schätzwerte betrachtet werden. Eine exakte Bestimmung der Zahl der de jure ernannten Militärgeistlichen dürfte kaum möglich sein. Sie würde allerdings auch die wechselseitige Durchlässigkeit von Feld- und Zivilseelsorge in einem Land, von dem größere Teile Kriegsgebiet oder frontnahes Gebiet waren, nicht beachten. 43 In der umfangreichen Sammlung von Pastoralberichten im Bestand OeSta KA AFV Akten finden sich seit 1915 Übersichten für Armeen, nach denen die Zahl hochgerechnet wurde.

44 Das galt insbesondere für die Standschützenbataillone im Alpenkrieg. Vgl. die Auflistung der jeweiligen Offiziere der Bataillone einschließlich der Feldkuraten bei 
war der Klerus der Habsburgermonarchie dagegen wie im Deutschen Reich vom Dienst im Krieg mit der Waffe befreit. Obzwar im Deutschen Reich von einem latent spannungsvollen Verhältnis zwischen katholischer Kirche und insbesondere dem evangelisch-preußischen Kaisertum gesprochen werden konnte, bestand an der Schätzung der Konfessionen als die Kriegsleistung begünstigenden Faktoren kein Zweifel. ${ }^{45}$ In Relation zur Truppenzahl war allerdings, mit Ausnahme Bayerns, die Militärseelsorge personell weit weniger gut ausgestattet. In der bayerischen Armee dienten insgesamt 571 Feldgeistliche, im restlichen Heer $1.441 .{ }^{46}$

Grundlegend für das Verständnis des Umfangs der habsburgischen Feldpastoral ist neben dem multikonfessionellen der multiethnische und multisprachliche Charakter der Monarchie. Insgesamt waren es 11 größere Sprachen: deutsch, italienisch, kroatisch, polnisch, rumänisch, ruthenisch, serbisch, slowakisch, slowenisch, tschechisch, ungarisch. Die Kommandosprache der Armee war deutsch, von den Soldaten wurde erwartet, einige wenige Dutzend Kommandos verstehen und befolgen zu können, während Offiziere neben dem Deutschen tunlichst die sogenannten Regimentssprachen beherrschen sollten. ${ }^{47}$ Anders verhielt es sich für die Militärgeistlichen. Im Sinn einer erfolgreichen Ausübung der Pastoral, es seien Predigt, persönliches Gespräch und - speziell für die katholische Seite - die Beichte genannt, sollten diese möglichst viele, der jeweiligen personellen $\mathrm{Zu}$ -

Wolfgang Joly, Standschützen. Die Tiroler und Vorarlberger Standschützen-Formationen im Ersten Weltkrieg. Organisation und Einsatz (= Schlern-Schriften, Bd. 303), Innsbruck 1998. Die Dichte der Betreuung im Gebirgskrieg war mit auf praktische Notwendigkeiten zurückzuführen.

45 Vgl. Lätzel, Katholische Kirche, S. 36-37; zur Haltung des Chefs des kaiserlichen Militärkabinetts Moritz von Lyncker vgl. Holger Afflerbach, „,Wenn man nicht in Allem, auch in dem Schwersten Gottes Hand erkennen will, ist man verloren“, in: ZIG 8 H. 2 (2014) S. 35-36.

46 Franz Albert, „Die katholische Seelsorge“, in: Max Schwarte, Der große Krieg 1914-1918. Bd. 10: Die Organisationen der Kriegführung, 3. Teil, Leipzig u.a. 1923, S. 221-243, S. 222 nennt für den Kriegsausbruch eine Zahl von 63 aktiven Militärgeistlichen, die Gesamtzahl ebd., S. 225.

47 Vgl. Peter Melichar / Alexander Mejstrik, „Die bewaffnete Macht“, in; Helmut Rumpler / Peter Urbanitsch (Hrsg.), Die Habsburgermonarchie 1848-1918, Bd. IX/2: Von der Stände zur Klassengesellschaft, Wien 2010, S. 1263-1326, S.1270. Vgl. die in OeSta KA Armeeoberkommando (= AOK) Operations-Abteilung (=Op.-Abt.) Akten Ktn. 91914 gesammelten Berichte, z. B. Generalmajor Birkenhain, 34. Infanterietruppen-Divisionskommando, 26.1.1915 Res. Nr. 492: „Die Sprachkenntnisse der Offiziere reichen nicht durchwegs aus, um die Mannschaft zu leiten und mitzureißen."“; Oberstleutnant $* * *$ [Name unleserlich], Infanterieregiment 58, 26.1.1915, es sei beim besten Willen meist unmöglich, den „Mangel der Sprachkenntnisse u[nd] deren suggestiven Einfluß auf die Mannschaft zu ersetzen.“ 
sammensetzung der Truppe entsprechende Sprachen gut beherrschen. ${ }^{48} \mathrm{Mehr}-$ sprachige Geistliche fanden sich kaum in den im Verhältnis zur Katholikenzahl priesterstarken Gebieten der Monarchie, die vor allem im Westen des Reichs gelegen waren und deren Priester in der Regel nur deutsch sprachen. ${ }^{49}$ Infolgedessen wurden Geistliche aus mehr oder minder priesterarmen Regionen wie Teilen Galiziens, dem adriatischen Küstenland oder Teilen Oberungarns herangezogen mit drastischen Folgen für die Zivilseelsorge. ${ }^{50}$ Überdies erforderte der beständige Wechsel in der Zusammensetzung von Kampftruppenteilen und in der Belegschaft von Militärspitälern die Notwendigkeit, deren konfessionelle wie sprachliche Zusammensetzung beständig im Auge zu behalten, um mit entsprechenden Versetzungen bzw. Neueinberufungen von Geistlichen reagieren zu können. ${ }^{51}$

Der durch die Sprachenvielfalt bedingte, sehr erhebliche personelle und organisatorische Aufwand hatte zur Folge, dass im Gefüge der österreichisch-ungarischen Armee in mehrsprachigen Truppenteilen oder Spitälern die Feldkuraten, eine positiv herausragende Ausnahme bildeten. ${ }^{52}$ Anders als die meisten

48 Minimum für die Ernennung zum Feldkuraten war die Kenntnis der deutschen und mindestens noch einer anderen in der Monarchie gesprochenen Sprache. Vgl. Dienstvorschrift für die [österreichisch-ungarische] Militärgeistlichkeit, Wien 1904, § 2 g, S. 2. 49 Vgl. die tabellarische Übersicht u. a. zur Zahl der Priester und Ordensmänner pro Katholiken für „Großregionen“ und Diözesen der Monarchie bei Klieber, Lebenswelten, S. 129.

50 Zwischen einzelnen Diözesen, militärischen Behörden und dem Militärbischofsamt entspannen sich fortlaufende Konflikte über Einberufungen. Die bei Manfried Rauchensteiner, Der Erste Weltkrieg und das Ende der Habsburgermonarchie 1914-1918, Wien 2013 beschriebene Auszehrung des Hinterlandes zugunsten der Armee - vgl. prägnant ebd., S. 826-827 - dürfte pars pro toto auf Zivil- und Militärseelsorge zutreffen. 51 Für die Kampftruppen der Armee vgl. die 30-seitige Übersicht Einteilung der Geistlichen nach Sprachen für die Armee im Felde [April 1917]. OeSta KA AOK Quartiermeister-Abteilung (=Q-Abt.) Akten Ktn. 1870 QNr. res. 43318/1917. In den Berichten der Spitalsgeistlichen war die konfessionelle und sprachliche Zusammensetzung der Insassen nachzuweisen, vgl. z. B. Feldkurat Dr. Paul Jarosa, Reservespital Prag Nr. 5, Konsignation über Nationalität und Religion der kranken Mannschaft [April 1916] OeSta KA AFV Akten Ktn. 219, für das Hinterland die Berichte des GKmdo Wien, z. B. MKmdo Wien an KM Abteilung 9, Wien im Mai 1916: Nachweisung des Präsenzstandes nach Religionen und Sprachen [des] Territorialbereiches Militärkommando Wien. OeSta KA GKmdo Wien Akten MA Ktn. 3135, 38-9-3-4. Darüber hinaus äußerten oftmals Feldkuraten den Wunsch versetzt zu werden, wenn ihre sprachlichen Fähigkeiten nicht angemessen waren.

52 Zur sprachlichen Zusammensetzung von Truppenteilen vgl. Helmut Rumpler / Adam Wandruszka (Hrsg.), Die Habsburgermonarchie 1848-1918. Bd. XI: Die Habsburgermonarchie und der Erste Weltkrieg, Teilbd. 2. Weltkriegsstatistik Österreich-Ungarn 1914-1918: Bevölkerungsbewegung, Kriegstote, Kriegswirtschaft, Wien 2014, S.147-155. 
Offiziere konnten sie sich zumeist mit der Truppe in deren Muttersprache verständigen. Für ihre Wirkung auf die Moral der Truppe konnte dieser Umstand ein bedeutender Faktor sein. In den Berichten der österreichisch-ungarischen Militärgeistlichen wird immer wieder betont, wie wichtig es für die Stimmung der Soldaten sei, wenn im Gottesdienst und im Gespräch die vertraute Sprache benutzt werde. ${ }^{53}$

\section{Offiziere}

Eine Verpflichtung der österreichisch-ungarischen Armee zur Ausübung der Feldpastoral lag in der offiziös gepflegten Religiosität des Herrschers und seines Hauses begründet. ${ }^{54}$ Aus Perspektive des traditionsgebundenen alten Kaisers war der Kirchgang der Soldaten eine Selbstverständlichkeit, dessen Ermöglichung - neben den Eingaben des zuständigen Militärbischofs - nicht zuletzt durch Interventionen von weiblichen Mitgliedern des Herrscherhauses immer wieder angemahnt wurde. ${ }^{55}$ Franz Josephs Nachfolger Karl intensivierte und modernisierte die Nutzung von Religion für den Erhalt der Moral der Truppe, so u.a. durch die von ihm durchgesetzte flächendeckende Errichtung von Soldatenheimen insbesondere für die Kampftruppen oder die Etablierung einer ebenfalls auf ihn zurückgehenden personalaufwendigen Heimkehrerpastoral. ${ }^{56}$ In Karls Auftrag sollten die zu Hunderttausenden aus russischer Kriegsgefangenschaft zu-

53 Vgl. z. B. Feldkurat Robert Vána, 6. Kavallerietruppen-Division, Pastoralbericht Januar 1916. OeSta KA AFV Akten Ktn. 217; Divisionspfarrer Josef Vampola, 1. Infanterietruppen-Division. Pastoralbericht Januar 1916. Ebd.; Feldkurat Stefan Proskurnicki, Landsturm-Infanterieregiment 22. Pastoralbericht Februar 1916. Ebd.

54 Vgl. Klieber, Lebenswelten, S. 101-102. - Die Präsenz von Geistlichen auf einem Schlachtfeld, die als ,Quasi-Militärs' mit der pastoralen Betreuung von Truppen betraut waren, ist keine Erfindung des 20. Jahrhunderts. In der Habsburgermonarchie, aber nicht nur dort begleiteten zahlreiche Kleriker Truppen in Kriegen der frühen Neuzeit und des 19. Jahrhunderts. Vgl. Franz Brendle / Anton Schindling (Hrsg.), Geistliche im Krieg, Münster 2009. Einige wurden zu legendenhaften Gestalten, die zur Nachahmung aufforderten, etwa Pater Johann Haspinger OFMCap im Tiroler Befreiungskampf 1809. 55 Vgl. z. B. die in Feldzeugmeister Böhm an AOK, Wien 29.4.1916. OeSta KA QAbt. Akten Ktn. 1682 QNr. 48739/1916 vorgetragene Beschwerde der Erherzogin Blanka.

56 Eine wesentliche Rolle für die Initiative pro Soldatenheime und deren Umsetzung hatte Pater Wilhelm Schmidt SVD, vgl. dessen Majestätsgesuch, St. Gabriel (Mödling) 10.12.1916 (Abschrift) in OeSta KA AOK Q-Abt. Akten QNr. 178274/1916 sowie seinen beiliegenden Entwurf für die Führung der Soldatenheime; kaiserlicher Befehl dazu OeSta KA AOK QAbt. QOp 178274/1916 Ktn. 1826. Zur Initiative Karls für die Heimkehrerseelsorge, nachdem der Militärbischof diese zunächst eher wenig hatte berücksichtigen wollen vgl. Bjelik an Arz [Chef des Generalstabs], Wien 8.3.1918 (Abschrift) Nr. 37144. OeSta KA AFV Akten 169. 
rückkehrenden Soldaten von eventuell vorhandenen defätistischen Einflüssen purgiert und für den Kampf vorbereitet werden.

Für den tatsächlichen Einfluss von Religion auf die Moral einer Truppe können, so ist jüngst argumentiert worden, als wichtige Zeugnisse entsprechende Aussagen von kommandierenden Offizieren herangezogen werden. ${ }^{57}$ Für die habsburgische Armee des Ersten Weltkriegs ist zunächst festzuhalten, dass ein quantitativ wohl bedeutender Teil des Offizierskorps areligiös und antireligiös eingestellt war. ${ }^{58}$ Als vorbildgebend zu nennen ist der langjährige Chef des Generalstabs, Generaloberst Franz Conrad von Hötzendorf. In seiner sozialdarwinistisch geprägten Vorstellungswelt war Krieg ,unvermeidlich, die Friedensgebote des Christentums oder des Buddhismus ebenso weltfremd wie Kants Idee des ewigen Friedens. ${ }^{\text {"59 }}$ Religion hatte für ihn im Krieg eigentlich keine Rolle zu spielen. Dennoch dürfte es trotz seiner ausgeprägten Skepsis für ihn und das Offizierskorps keine andere Option gegeben haben, als im Kontext der Monarchie die Feldpastoral zumindest zuzulassen.

Das bedeutete allerdings keine Förderung. Im Kriegsalltag sind zahlreiche Einschränkungen festzustellen. So konnte für den Zeitpunkt eines Sonntagsgottesdienstes Dienst angesetzt werden, während einer religiösen Feier in nächster Nähe Pferde beschlagen, oder, weit im Hinterland, direkt neben einer Kirche während eines Gottesdienstes Gefechtsübungen abgehalten werden. ${ }^{60}$ Allgemein bestritten wurde der Wert von Militärgeistlichen von einem Divisionskommandeur, der sie als unterbeschäftigt ansah und als Verwalter der Offiziersmenage verwendet sehen wollte. ${ }^{61}$ In den ersten Monaten des Krieges gab überdies eine Umfrage des Armeeoberkommandos unter den Kommandeuren bis hinab zur Brigadeebene ein eher ambivalentes Bild über den Stellenwert der Militärgeistlichen ab. Während manche sie zusammen mit den Militärärzten aufgrund der Gefahren, denen sie ausgesetzt waren, zur kämpfenden Truppe zu rechnen sahen,

57 Vgl. Hassner, Religion on the Battlefield, S. 107. Bei Martin Schmitz, „Als ob die Welt aus den Fugen ginge". Kriegserfahrungen österreichisch-ungarischer Offiziere 19141918 (= Krieg in der Geschichte, Bd. 86), Paderborn u. a. 2016, S. 357-358 ist Religion nur erwähnt als Mittel zur psychischen Bewältigung des Krieges durch Offiziere.

58 Zur geringen Bedeutung für den Offiziersnachwuchs vgl. die Erfahrungen von Pero Blaskovic, Mit den Bosniaken im Weltkrieg. Auszüge aus „Sa Bosnjacima U Svejtskom Ratu“, Wien 2001, S. 37.

59 Kronenbitter, „Krieg im Frieden“, S. 135-136.

60 Vgl. Feldkurat Nikolaus Prytulak, Landwehr-Infanterieregiment 34, Pastoralbericht April 1916. OeSta KA AFV Akten Ktn. 219; Divisions-Pfarrer Paul Laktis, 10. Kavallerie-Division, Pastoralbericht Juli 1917. OeSta KA AFV Akten Ktn. 231; Provinzial Pater Albertus M. Hauser SDS an Militärkommando Wien, Wien 30.9.1916. OeSta KA GKmdo Wien Akten MA Ktn. 3135, 38-2-10.

61 Vgl. Feldmarschallleutnant Urbánski, Kmdo. 46. Schützendivision an AOK, 12.8.1917. OeSta KA AOK Q-Abt. Akten Ktn. 1966 QNr. 139254/1917. 
wollten andere sie mit Verwaltungsbeamten gleichstellen und ihnen überhaupt den militärischen Rang absprechen. ${ }^{62}$

Im weiteren Verlauf des Krieges zeigt sich jedoch ein durch die Kriegserfahrungen geändertes Bild in Form einer positiveren Einschätzung der Bedeutung von Religion im Krieg. Entscheidend für die Möglichkeiten der Feldpastoral war, daran kann für alle kriegführenden Mächte kein Zweifel bestehen, die jeweilige Haltung der Divisions- und Regimentskommandeure sowie der Spitalskommandanten. ${ }^{63}$ Waren diese religiös affin, nahmen auch selbst an religiösen Feiern und Gottesdiensten teil, so war die Teilnahme von Offizieren und in geringerem Maße dem Pflegepersonal eine hohe und die Bedingungen für die Seelsorge relativ gut. Darüber hinaus schätzten konfessionell nicht gebundene Offiziere den positiven Einfluss der Feldseelsorge auf die Durchhaltefähigkeit der Soldaten. Belegt wird dies durch etliche Zeugnisse von Kommandeuren, die entweder allgemein gehalten sind oder in denen sie sich über das Wirken einzelner Kuraten äußern, ohne dass diese Kuraten in ihren Pastoralberichten den jeweiligen Offizier als religiös gesinnt bezeichnet hätten. In den Akten des Wiener Kriegsministeriums, des kaiserlich-königlichen Landwehrministeriums sowie des Militärbischofs wird dies besonders deutlich, wenn anlässlich von Versetzungen, Verwundungen, Verdächtigungen etc. von Kommandeuren Zeugnisse auszustellen waren. Neben negativen Beurteilungen von Geistlichen, die häufig dennoch die Wichtigkeit der Funktion der Militärgeistlichen hervorheben, finden sich umfassende Würdigungen des Wirkens durch etliche Kommandeure von Truppenteilen. $^{64}$

Einzelne Offiziere wie Generalmajor Alfred von Boog, Kommandeur der 25. Infanteriedivision, setzten die Feldpastoral darüber hinaus zur Bearbeitung die Kohäsion der Armee bedrohender ethnischer Konfliktlinien ein. Bekannt ist das

62 Vgl. die Berichte in OeSta KA AOK Op.-Abt. Akten Ktn. 91914.

63 Für die Kampftruppen pointiert beschrieben bei Johann Parsch, Aufgaben des Feldseelsorgers an der Front, in: Pastoralblatt für die k.u.k. Militär- und Marinegeistlichkeit 1916 Nr. 2, S. 3-17, S. 6; für die Spitalskommandanten die Bewertungen in den Berichten der Militärgeistlichkeit. Vgl. für Frankreich Boniface, L'aumônerie, S. 71, für Italien Della Rocca, La fede e la guerra, S. 46-53.

64 Vgl. u.a. Major Reimann, Schützenregiment 18 an 45. Schützendivisionskommando, 18.4.1917. OeSta KA AFV Akten Ktn. 180; Feldmarschallleutnant Kalser, 13. Schützendivision an 4. Armeekommando, 19.4.1917 res. 106, ebd.; Generalmajor Metz, 11. Infanteriedivision an 4. Armeekommando, 24.4.1917, ebd. Major Stein an Rayonskommando 5, 3.8.1916 res. 218. OeSta KA Landesverteidigungsministerium Akten Ktn. 2389 1916, der bisherige griechisch-katholische Feldkurat Martynik habe im Sinne „einer sehr eindringlichen Einwirkung“ gute Arbeit geleistet, sei nun aber durch „Aufregung“ nach Beschuß unbrauchbar für den Dienst. Während des Krieges wurden Stimmen von höheren Offizieren publiziert in Ruhmesblätter der k.u.k. Militär- und Marinegeistlichkeit aus dem Weltkrieg 1914-17, Wien 1917. 
angebliche Versagen zweier vor allem aus tschechischen Soldaten gebildeter Regimenter an der russischen Front, die dort nahezu kampflos geschlossen übergelaufen seien. ${ }^{65}$ Beide Regimenter wurden offiziell aufgelöst, die Fahnen in das Heeresgeschichtliche Museum in Wien gegeben. Als Rest eines Regiments blieb ein Bataillon bestehen, das 1916 zu Boogs Division gehörte. Um dessen Moral zu steigern, wurde ein tschechischsprachiger Kurat angefordert, der die Soldaten mehrmals in mehrtägigen Exerzitien belehrte und ermunterte. ${ }^{66}$ Möglicherweise wurde diese Praxis auf weitere Teile der Front ausgeweitet. Ein Einzelfall war dagegen nach gegenwärtigem Kenntnisstand der schonende Umgang mit Soldatenleben durch die religiöse Bindung eines höheren Kommandeurs. Bei zu waghalsig erscheinenden geplanten Unternehmen appellierte der Divisionsadjutant fallweise an dessen Gewissensbelastung, woraufhin einige Male die Absage erfolgte. ${ }^{67}$ Gängiger dürfte eine Haltung wie die des genannten britischen Kommandeurs Haig gewesen sein, der sich kurz vor der Somme-Offensive im Vertrauen auf Gott eine reine, religiös gefestigte Disposition attestierte. $^{68}$

\section{Pastoral im Krieg, Krieg und Pastoral}

Der Wert von Religion für die Kampfmoral der Truppe wurde von kirchlichreligiöser Seite her als solcher gesehen. Die Seelsorge war mit den Worten des Armeeoberpfarrers Friedrich Albert ,wie alles übrige ... nur Mittel zu dem gleichen Zweck, den Gegner zu vernichten, wo man auf ihn trifft, und koste es, was es wolle." ${ }^{69}$ Wenn der österreichisch-ungarische Feldkurat Johann Parsch

65 Vgl Richard Lein, Pflichterfüllung oder Hochverrat? Die tschechischen Soldaten Österreich-Ungarns im Ersten Weltkrieg (= Europa Orientalis, Bd. 9), Münster u. a. 2011. 66 Vgl. AOK an Heeresgruppenkommando Erzherzog Eugen, 1. bis 5., 7., 10. und 11. Armee, Q-Abteilungen 6, 8 und 9, Landesverteidigungskommando Tirol, 19. Korpskommando, 23.5.1916. OeSta KA AOK Q-Abt. Akten Ktn. 1683 QNr. 50058/1916; Feldoberkurat Karl Kolisek an AOK, QAbt., 9.10.1916. OeSta KA Q-Abt. Akten Ktn. 1774 QNr. 124982/1916; Generalmajor Boog an AOK, 12.4.1917. OeSta KA AOK Q-Abt. Akten Ktn. 1905 QNr. res. 79803/1917.

67 Vgl. Peter Broucek (Hrsg.), Ein General im Zwielicht: die Erinnerungen Edmund Glaises von Horstenau. Bd. 1: K. u. k. Generalstabsoffizier und Historiker (= Veröffentlichungen der Kommission für Neuere Geschichte Österreichs, Bd. 67), Wien 1980, S. 309.

68 Kurz vor Beginn der Offensive schrieb Haig an seine Frau: „,I think it is ... Divine help which gives me tranquility of mind, and enables me to carry on without feeling the strain of responsibility to be too excessive. I try to do no more than do my best and trust to God.“ Zit. nach Hugh Sebag-Montefiore, Somme: Into the Breach, Cambridge (Mass.) 2016, S. 27.

69 Albert, Handbuch, S.112. 
seine gesamten pastoralen Bemühungen so einordnete: „Die Hauptsache ist und bleibt im Krieg eben der Krieg “ ${ }^{70}$ dann hatte er gleichfalls diese funktionale Seite der Feldpastoral benannt. Die auch in folgenden Abschnitten des Beitrags weiter zu erläuternde Sorge um das Seelenheil der Soldaten war allerdings nicht allein Mittel zum Zweck, sondern verfolgte ihre eigenen Ziele. Wie die verwendeten Termini belegen, wurde die katholische Feldpastoral analog zur ,normalen“ Zivilpastoral gesehen, gelegentlich war von der Diözese des Militärbischofs die Rede, ebenso waren die der Seelsorge eines Feldgeistlichen anvertrauten Soldaten dessen „Pfarrkinder“, er der „Hirte“, sie seine „Herde“ ${ }^{71}$ Die Pflichten eines Militärgeistlichen im Krieg entsprachen jenen eines jeden anderen Geistlichen, Spendung der Sakramente, Predigt, Gebet, Beerdigungen, die Ausübung von geistlichen und leiblichen Werken der Barmherzigkeit. ${ }^{72}$ Wie Jesus soll der Geistliche durch Person und Wirken ,allen alles werden und dennoch überall entbehrlich erscheinen“. ${ }^{73}$ In national und regional unterschiedlichen Schattierungen hatten die katholischen Geistlichen in Person im Krieg wie in der Zivilpastoral um 1900 für die Perpetuierung der katholischen Lebenswelt einzustehen. ${ }^{74}$ Insgesamt wären die Erfüllung des religiösen Auftrags durch die Militärgeistlichkeit und die Funktionalisierung für die Moral der Truppe aber als Parallelaktion nur unzureichend verstanden, sie waren vielmehr stets untrennbar aufeinander bezogen. ${ }^{75}$

Daraus folgt zunächst, dass die Feldpastoral nur in ihrem Kontext verstanden werden kann, den Realitäten und dem Verlauf des Krieges. Neben der angesprochenen höheren Bewertung von Religion durch Offiziere wie Haig, den bayrischen Divisionär oder habsburgischen Kommandeuren gilt dies für die Rückwirkungen auf die Organisation der Seelsorge. Trotz der herausragenden Bedeutung der Materialschlachten des Jahres 1916 im Westen (Verdun, Somme) und der Isonzo-Schlachten 1915-1917 sind diese in ihrer Bedeutung für die Mi-

70 Parsch, Aufgaben des Feldseelsorgers, S. 13.

71 Vgl. Divisionspfarrer Josef Lukášek, 92. Infanterietruppen-Division, Pastoralbericht Januar 1916. OeSta KA AFV Akten 217; Divisions-Pfarrer Stanislaus Rygielski, 64. Infanteriedivision, Pastoralbericht November 1917. OeSta KA AFV Akten Ktn. 235; für die deutsche Armee Bericht der Militärpfarrerkonferenz in Laon 20.4.1915. BA MA PH 32, 390: Feldgeistlicher Alfons Helmer, 44. Reserve-Division, Bericht, Sedan 13. 6.1916. BA MA PH 32, 264.

72 Dienstvorschrift 1904, § 19, S. 18 f.

73 Albert, Handbuch, S. 2.

74 Die von Klieber, Lebenswelten, S. 104 benannte „Gleichzeitigkeit von Ungleichzeitigem par excellence“ dürfte erst recht zutreffen, wenn sich der Blick auf katholische Lebenswelten in Europa insgesamt richtet. Gleichwohl wäre die Rolle des Klerus seit dem Trienter Konzil im o. a. Sinn zu kennzeichnen.

$75 \mathrm{Vgl}$. in diesem Sinn für die Militärgeistlichen allgemein Hassner, Religion on the Battlefield, S. 87-109. 
litärgeistlichen bisher nicht adäquat berücksichtigt worden. Wie bekannt ist, hat das Hauptquartier der britischen Armee in Vorbereitung der Somme-Offensive alles versucht, organisatorische Grundlagen für eine Zusammenarbeit zwischen Militärgeistlichen, Offizieren und Kampftruppen zu etablieren, die es so vorher nicht gegeben hatte. Tatsächlich hatten britische Divisionen zu diesem Zeitpunkt ebenso viele, teils mehr Militärgeistliche zur Verfügung als die österreichischungarischen. ${ }^{76}$ Auch wenn die Offensive unter entsetzlichen Verlusten auf beiden Seiten scheiterte, erwiesen sich die Aktionen zahlreicher britischer Geistlicher als effektiv im militärischen Sinn. Auf deutscher Seite sind für die Schlacht um Verdun 1916 und die Somme-Offensive ebenso Folgewirkungen zu verzeichnen. Unter den Bedingungen der relativen Personalknappheit und der Situation im Kampfraum wurden Seelsorgern fixe Sektoren zugewiesen, in denen in der Regel viele Soldaten massiert waren, die sie flexibel zu pastorieren hatten. ${ }^{77}$ Neben dem Versuch, Abhilfe für die relativ geringere Zahl von Militärgeistlichen zu schaffen, ist von einem Anpassungsprozess zu sprechen, der in gewisser Weise parallel zu jenem der deutschen Armee gesehen werden kann. ${ }^{78}$

Ein Effekt der Isonzo-Schlachten für die österreichisch-ungarische Militärseelsorge ist nicht auf den ersten Blick zu erkennen. Ein Grund war, dass die organisatorische Struktur fixiert war und es darüber hinaus für die eigenen Militärgeistlichen in Form von umfangreichen Handbüchern und Dienstanweisungen aus der Vorkriegszeit sowie deren ausführlicher Explikation im Krieg ausführliche Vorgaben für die Praxis gab. ${ }^{79}$ Die extensive Kodifizierung, eine Be-

\section{Vgl. Snape, God and the British Soldier, S. 91.}

77 Vgl. die Zusammenfassung der Erfahrungen an der Somme und in Verdun durch Armeeoberpfarrer Middendorf. Konferenz der Feldgeistlichen der Armeeabteilungen A und B in Straßburg, 15.3.1917. BA MA PH 32, 390; Bericht des Divisionspfarrers Hellinger 1. Gardereservedivision. Tagung der Feldgeistlichen der 4. und 6. Armee, Gent 28.3.1917. Ebd.; Oberst v. Redern, Quartiermeister 4. Armee, 28.4.1918 Abt. IV e kath. Tgb. Nr. 1094 evg. Tg. Nr. 895. Erlaß Regelung der Seelsorge während der Kämpfe. BA MA PH 32, 17.

78 Vgl. Stachelbeck, Heer und Marine, S. 55-56.

79 Neben der genannten Dienstvorschrift das lexikalische, von Bjelik verfasste Handbuch für die k.u.k. katholische Militärgeistlichkeit, Wien 1905 sowie das Dienstbuch A-16f. Bestimmungen für die Militärseelsorge und die Matrikelführung im Kriege, Wien 1914. Während des Krieges wurden zahlreiche Weisungen an die Feldgeistlichen gegeben, einige davon im Druck zu finden im Pastoralblatt für die k.u.k. Militär- und Marinegeistlichkeit. Nach gegenwärtigem Kenntnisstand scheint es so, dass die habsburgische Militärgeistlichkeit die einzige war, die derart ,ausgestattet' in den Krieg zog. Für Großbritannien vgl. Snape, God and the British Soldier, S. 91, für das preußische Heer eine analog zu Großbritannien nicht kriegstaugliche Ordnung. Vgl. Katholische militärkirchliche Dienstordnung mit Ausführungsbestimmungen, Berlin 1902. In Frankreich und Italien konnte es aufgrund der Etablierung der Militärseelsorge erst mit dem Krieg keine Bestimmungen geben. 
sonderheit der habsburgischen Feldpastoral, hatte ihre Vor- und Nachteile. Von Vorteil konnte es sein, wenn schlicht nachgelesen werden konnte, was in bestimmten Fällen zu tun war. Die aktive, aber zahlenmäßig geringe Militärgeistlichkeit erwies sich darin als insgesamt geschult. Die Masse des habsburgischen Feldklerus rekrutierte sich aber aus Geistlichen des Reservestandes, die oftmals, wie in den Anfängen und im Kriegsverlauf deutlich wurde, von manchen Vorgaben wenig Ahnung hatten und erst in diese eingewiesen bzw. mit den bald hinzukommenden Explikationen instruiert werden mussten. Weiter wäre die ausgeprägte Papierlastigkeit des k.u.k. Militärs und seiner Bürokratie anzuführen, die Ausdruck einer Kultur der Weisungsgebundenheit war. ${ }^{80}$ In den Geschäftsbüchern des österreichisch-ungarischen Feldbischofs findet diese Tatsache ihren Niederschlag in einer ungeheuren Vermehrung der ein- und ausgehenden Schriftstücke. ${ }^{81}$ Aus diesem und einem weiter unten anzuführenden Grund waren die österreichisch-ungarischen Militärgeistlichen mit einem überkomplexen Normensystem konfrontiert, dem immer wieder nicht genügt werden konnte. Den resultierenden Pressionen suchte man sich so gut es ging, häufig mit Verweis auf die Kernaufgabe ,Seelensorge', zu entziehen.

Eine Konzentration auf das Wesentliche wäre ein Fortschritt gewesen. Eben dies geschah durch eine 15-seitige, ursprünglich von einem an der Isonzofront eingesetzten Feldkuraten verfasste Broschüre, die für die Militärgeistlichen aller Konfessionen vom habsburgischen Armeeoberkommando (AOK) 1917 herausgegeben wurde. ${ }^{82}$ Einleitend wird in ihr der Wert der Gottesfurcht betont als

Grundlage eines moralischen Lebenswandels und eine Aneiferung zur treuen Erfüllung der Pflicht. Grundsätze, die den Menschen zum strengen Erfassen seiner Obliegenheiten anspornen, ihn in den Beschwerlichkeiten des Lebens unterstützen, seinen Mut beleben, ihm Beruhigung in Gefahren und Trost im Unglücke bieten, müssen geehrt und gepflegt werden. Die Pflege der Gottesfurcht ist bei der Armee im Felde von ganz besonderer oft ausschlaggebender Wichtigkeit.

80 Vgl. prägnant die Unterschiede zwischen reichsdeutschen und habsburgischen Offizieren hervorhebend den Bericht des zu deutschen Kommandos detachierten k.u.k. Generalstäblers Major Erwin Freiherr von Franz o.D. [1914/15]. OeSta KA AOK OpAkten Ktn. 9 1914, die Auswirkungen bei Schneider, Kriegserinnerungen, S. 242.

81 Vgl. den Hinweis bei Lipusch, Militärseelsorge, S. 38 auf eine Vervielfachung der Geschäftszahlen. Die Zahl der Ein- und Ausgänge geht darüber hinaus, sie überschritt seit 1915100.000 pro Jahr. Soweit sich es anhand der überlieferten Geschäftsbücher und Akten der preußischen Feldpropstei sagen lässt, hatte diese mit einem Bruchteil dessen zu tun.

82 Vgl. Behelf für die Pastorierung der Armee im Felde [1917]. OeSta KA AOK QAbt. Akten Ktn. 1966 QNr. 139392/1917. Die folgenden Zitate ebd. Der Behelf wurde in 5.000 Exemplaren gedruckt und an sämtliche Militärgeistlichen sowie an die Kommandeure von Truppenteilen bis auf Bataillonsebene und an Spitalskommandanten verteilt. 
Daher haben die Kommandanten Gelegenheit zum Gottesdienst zu geben, die Soldaten haben diese Gelegenheit zu nützen. Als Merkmal der k.u.k. Pastoral auch im Unterschied zum deutschen Bündnispartner - galt, es solle „Zwang zur Erfüllung der religiösen Pflichten ... niemals ausgeübt werden." Freiwillige Teilnahme am Gottesdienst war die Vorgabe. Habe „der Seelsorger das Vertrauen der Mannschaft einmal gewonnen, so werden die Leute auch ohne Befehl, nur auf das bloße Aviso dem Gottesdienste beiwohnen." Unterschieden werden weiter in der Instruktion die verschiedenen Situationen, in denen sich die Truppe befinden kann, Kampfzone, Ruhestellung, Etappe und Hinterland. Für die Kampfzone selbst wird der Wert der Religion am deutlichsten akzentuiert:

Der Soldat, welcher in der Zone der Kampftruppen oft übermenschlich schweren Dienst $\mathrm{zu}$ versehen hat, bedarf vor allem einer hohen moralischen Kraft und des religiösen Trostes. ... Ein religiös denkender Soldat mit ruhigem Gewissen kämpft besser als ein etwa gedrückter Mann.

Das ruhige Gewissen, das jedenfalls dem Katholiken sagte, im Fall seines Todes erwarte ihn das ewige Leben, konnte er vornehmlich in der Ruhestellung erneuern und befestigen. ${ }^{83}$

Auch über den Krieg hinaus wurde gedacht, im Etappenraum solle „der Seelsorger trachten, religiös-sittliche Menschen $\mathrm{zu}$ erziehen, welche nicht nur momentan ihren Dienst ordentlich versehen, sondern auch im Frieden sich noch als gute, patriotische Staatsbürger betätigen werden.“ Die Unterscheidung zwischen verschiedenen Situationen, in denen die Feldpastoral je spezifisch auszuüben war, entsprach den bisherigen Erfahrungen des Krieges und konnte als situativ angemessen bezeichnet werden. Zu Beginn des vierten Kriegsjahres musste aber im Hinblick auf die Verstetigung des „Durchhaltens“ wohl unbedingt betont werden, es sei das „Leben noch immer nicht das höchste Gut des Menschen".

\section{Militärseelsorger}

Die Funktionalisierung von Religion im Weltkrieg bedingte eine nachhaltige Inanspruchnahme von Amt, Person und Praxis der Militärgeistlichen. Die Grausamkeit des Krieges, die Sinnlosigkeit vieler Tode im Verhältnis zu ihrer Effektivität für den Verlauf einer Schlacht und das Verhalten mancher Geistlicher verminderten zweifellos die Überzeugungskraft von Religion für die Moral von Kombattanten. Der Glaube an einen persönlichen Gott schien einem Tiroler

83 „Während der Retablierung ist es die vornehmliche Pflicht des Militärseelsorgers, den eventuell abgekämpften Truppen neuen Mut, neues Gottvertrauen und neue Opferwilligkeit einzuflößen und ihre eventuell gesunkene Moral aufs neue zu heben. “Ebd. 
Kaiserjäger angesichts gesammelter Kriegserfahrungen nicht mehr möglich, ${ }^{84}$ einem anderen erschien das Beichthören der Feldkuraten nach einem völlig sinnlosen Angriff mit zahlreichen Toten als oberflächlich. ${ }^{85}$ Während der 10. Isonzo-Schlacht im Mai 1917 zuckte und wand sich der „Himmelskutscher“ des k.u.k Landsturm-Infanterieregiments 27 bei jeder Granate, heftig konfrontiert damit, „der Mannschaft ein so schlechtes Beispiel zu geben, ... [zog er vor] zu erklären, er fürchte sich schrecklich vor dem Schießen. Fressen tut er für 2, saufen und rauchen für 10, fürchten aber für hundert. "86 Solche - nach Ansicht anderer Kombattanter - als Feigheit zu interpretierenden Akte, das Auslassen des eigentlich regelmäßig gewünschten Besuchs der Schützengräben trugen ebenso zu einem Abbau der Bindekraft von Religion bei wie die allerdings seltene Misshandlung von Mannschaften und die sehr viel häufigeren Fälle von Trunkenheit oder sexueller Devianz. ${ }^{87}$

Dennoch konnten Militärgeistliche durch ihre Person und ihr Verhalten, so erstaunlich es angesichts ihrer kriegslegitimatorischen Funktion klingen mag, als ein Gegengewicht gegen die Folgen des Krieges wirken. Einer der wichtigsten die Moral herabsetzenden Faktoren während eines jeden Krieges sind die Einsicht und das Gefühl, von fernen und nahen Vorgesetzten falsch geleitet oder gar ,verraten' worden zu sein. ${ }^{88}$ Militärgeistliche waren in der habsburgischen Armee - wie in anderen Armeen des Weltkriegs - Offiziere, in diesem Fall mit dem Einstiegsrang eines Hauptmanns. ${ }^{89}$ Zwischen Offizieren bis hinab zum Fähnrich und Soldaten herrschte eine immense, nachgerade menschenverachtende Kluft. ${ }^{90}$

84 Vgl. Johann Mittermaier, Die Schrecken des Krieges. Erinnerungen eines Südtiroler Kaiserjägers aus dem 1. Weltkrieg, Brixen 2005, S. 98-99.

85 Vgl. Matthias Ladurner-Parthanes, Kriegstagebuch eines Kaiserjägers, Bozen 1996, S. 37-47 zum Angriff, 49-50 zum Beichthören.

86 Volker Rutte (Hrsg.), Die Kriegstagebücher des Franz Matthias Hartinger, Offiziersstellvertreter im k.k. Landsturm-Infanterie-Regiment Laibach No. 27, Graz 2012, S. 169.

87 In den Akten des Kriegsministeriums, des Landwehrministeriums und des Apostolischen Feldvikars finden sich viele Fälle von Trunkenheit und sexueller Devianz bei Feldkuraten. Hašeks Kunstfigur Otto Katz kann in dieser Hinsicht als Idealtypus bezeichnet werden.

88 Vgl. Jonathan Shay, Achilles in Vietnam. Combat Trauma and the Undoing of Character, New York 1994, S. 10-14.

89 Die französischen Militärgeistlichen bezogen ein Hauptmannsgehalt, hatten aber nicht den Hauptmannsrang, die italienischen den Leutnantsrang, die aktiven deutschen Feldgeistlichen waren „obere Militärbeamte im Offiziersrange“ Vgl. Boniface, L'aumônerie, S. 99, Della Rocca, La fede et la guerra, S. 46, für das deutsche Heer Militärkirchliche Dienstordnung, § 45, S. 10, Vogt, Religion im Militär, S. 453-454, 489.

90 Vgl. Eintrag Johann Parsch, Kriegstagebuch Juli 1916: „Ich dachte: im Krieg finden sich Mann und Offizier zusammen; das ist nicht der Fall. Der Mann wird angeschrien, beschimpft, geohrfeigt, geschlagen, angebunden.... die Offiziere bekommen Brot, Wein, 
Die erst spät im Krieg abgeschaffte Praxis des Anbindens, eine ausgeprägte Bevorzugung der Offiziere bei der Verköstigung selbst in Zeiten des Hungers und die offene Missachtung von Mannschaftsverlusten stellten das Vertrauen der Soldaten auf eine enorme Belastungsprobe. ${ }^{91}$ Aus einer Vielzahl von Berichten geht hervor, wie die Mannschaften positiv auf die Bemühungen von Feldkuraten um sie reagierten. Diese konnten z. B. in der Hilfe bei persönlichen Problemen bestehen, Analphabeten das Lesen und Schreiben beizubringen, dem erwähnten Austausch in der Muttersprache, Organisation von Rauch- und Esswaren, Besorgung von Lektüre, Errichtung von Soldatenheimen oder ein würdiges Begräbnis von Kameraden. ${ }^{92}$ In Grenzen konterkarierten Feldgeistliche damit, obwohl sie selbst Offizier waren, den vielfach erlebten Verrat durch Obrigkeit und Offizierskorps.

Nichts war darüber hinaus bei Kampftruppen überzeugender als das Beispiel von Militärgeistlichen, die ihren pastoralen Auftrag in überzeugender Weise in der Kampfzone einschließlich der Sanitätsanstalten ausübten. ${ }^{93}$ Ein Feldkurat berichtete z.B. 1916, wie positiv es auf die Soldaten wirke, wenn er sie

Zigaretten, Geld, und die Mannschaft muß darben. Ein Stück hartes Fleisch, daß man oft nicht essen kann, Suppe, die nicht zu genießen ist.“ Zit. nach: Norbert Höslinger, „Der Lebensweg von Pius Parsch“, in: Norbert Höslinger / Theodor Maas-Ewerd (Hrsg.), Mit sanfter Zähigkeit: Pius Parsch und die biblisch-liturgische Erneuerung (=Schriften des Pius-Parsch-Instituts Klosterneuburg Bd.4), S.13-78, S.33. Der Klosterneuburger Chorherr Parsch (Ordensvorname: Pius), 1915-1918 Feldkurat des Infanterieregiments 93, war nach dem Krieg einer der Wegbereiter der Liturgischen Bewegung.

91 Beobachtungen dazu finden sich in vielen Tagebüchern, etwa bei Ladurner-Parthanes, Kriegstagebuch, S. 185-186. Die habsburgische Armee stand damit nicht alleine da. Zur italienischen Armee vgl. Cramer, Dynamic of Destruction, S. 127-128.

92 Vgl. z. B. Feldkurat Josef Kovács, Honved-Infanterieregiment 20, Tätigkeitsbericht, 1.4.1915. OeSta KA AFV Akten Ktn. 215; Feldkurat Dr. Josef Révai, Reservespital Naránscebes, Pastoralbericht Januar 1916. OeSta KA AFV Akten 217; Divisions-Pfarrer Johann Folba, 15. Infanterietruppen-Division, Pastoralbericht April 1916. OeSta KA AFV Akten Ktn. 219; Feldsuperior Viktor Várady, 2. Armee, Bericht als Beitrag zur Kriegsgeschichte o.D. [Juli 1917]. OeSta KA AFV Akten Ktn. 180; Feldkurat Johann Parsch, Infanterieregiment 93, Pastoralbericht April 1918. OeSta KA AFV Akten Ktn. 240. Vom Apostolischen Feldvikar wurde ein ,liebevolles‘ benehmen gegenüber den Soldaten und der Einsatz für ihre Belange öfters angemahnt, vgl. z. B. Bjelik an Feldsuperiorate im Felde und im Hinterland, Wien 10.8.2016. Nr. 52703 res. OeSta KA AFV Journal 1916.

93 In den Pastoralberichten an den österreichisch-ungarischen Militärbischof wurde für die Geistlichen der Kampftruppen abgefragt, ob regelmäßig der Schützengraben besucht werde. Für die italienischen Militärgeistlichen in diesem Sinn Della Rocca, $L a$ fede e la guerra, S. 54-63. 
in kleinen Partien in den granatsicheren Unterständen versammelt, wo ihnen eine Predigt gehalten wurde, danach hatten sie Gelegenheit zur Osterbeicht, und am anderen Morgen hatte die gleiche Abteilung ebenfalls im granatsicheren Unterstande im vordersten Schützengraben, stellenweise nur 30-40 Schritte vom Feind entfernt, hl. Messe mit Predigt und Osterkommunion. ${ }^{94}$

Auf dem Sanitätsplatz, so hatte er im Vormonat berichtet, galt seine Tätigkeit neben dem Versehen von schwerverwundeten oder sterbenden Soldaten der Mithilfe bei ihrer Versorgung. ${ }^{95}$ Überzeugend wirkten auf die Truppe auch humane Aktionen für und gegenüber dem Feind wie den Aufruf eines Geistlichen an wieder einmal in einen aussichtslosen Angriff getriebene italienische Truppen das Feuer einzustellen und sich zurückzuziehen, um nicht sämtlich sinnlos abgeschlachtet zu werden, ebenso die mutige Rettung eigener zwischen den Linien liegen gebliebener Verwundeter. ${ }^{96}$

Ungeachtet der Frage nach dem Verfall der Bindekraft von Religion für Soldaten und Offiziere lässt sich ein ,Breaking Point' für die habsburgische Feldgeistlichkeit auf den Spätwinter 1917/18 und das Frühjahr 1918 datieren. An erster Stelle zu nennen ist die physische und psychische Erschöpfung zahlreicher langgedienter Geistlicher insbesondere in Kampfeinheiten. Eine vom Militärbischof initiierte, vom Armeeoberkommando genehmigte Austauschaktion mit Kuraten aus dem Hinterland brachte teilweise Entlastung, ohne einen generellen Zustand der Endlichkeit pastoraler Bemühungen verdrängen zu können. ${ }^{97}$ Denn zweitens war das Gefühl der Erschöpfung jeglicher Ressourcen bei vielen Militärgeistlichen überwältigend. Wie es der langjährige Pfarrer der k.u.k. 1. Infanteriedivision formulierte: „Ich kann den Jammer nicht mehr mit ansehen.“98

94 Feldkurat Karl Schmitz, Landsturm-Infanterieregiment 1, Pastoralbericht April 1916. OeSta KA AFV Akten Ktn. 219.

95 Vgl. Feldkurat Karl Schmitz, Landsturm-Infanterieregiment 1, Pastoralbericht März 1916. OeSta KA AFV Akten Ktn. 219.

96 Vgl. Emilio Lussu, Un Anno sull' Altopiano, Turin 1999, S. 110; Bericht Feldkurat Franz Josef Hämmerle vom Mai 1917, Druck: Lipusch, Militärseelsorge, S. 363-364.

97 Zur Initiative vgl. Bjelik an alle Feldsuperiorate im Feld und der Militärgouvernements, Wien 19.7.1917. OeSta KA AFV Bücher Journal 1917, Nr. 61442 bis 61456. Aber erst im o. a. Zeitraum wurde von zahlreichen Kommanden bzw. Feldkuraten um Versetzung in das nichtaktive Verhältnis oder den Austausch mit einem Kuraten des Hinterlandes gebeten. Vgl. z. B. das Zeugnis des Kommandos der 25. Infanteriedivision für ihren langjährigen Divisionspfarrer Bartholomäus Boross vom Januar 1918. OeSta KA KM Abt. 9 Akten 1918 Ktn. 1367, 17-2-3.

98 Divisions-Pfarrer Feldoberkurat Josef Vampola an AFV, 28. 2.1918. OeSta KA KM Abt. 9 Akten 1918 Ktn. 1382, 18-9-130. Zur ähnlich gelagerten Krise des italienischen Feldklerus vgl. Della Rocca, La fede et la guerra, S. 115-132. 


\section{Himmel und Tod}

Unter den Bedingungen dieses Krieges schien vielen Soldaten der Tod wahrscheinlicher als das Überleben. Vom Tragen von Amuletten oder angeblich altbewährten Himmelsbriefen bis hin zum Einsenden von Fotos an die Muttergottes im Kloster Einsiedeln (Schweiz) reichten bei Soldaten verschiedener Nationalitäten Versuche, sich eines besonderen Schutzes gegen dieses Schicksal zu versichern. ${ }^{99}$ Aus Perspektive der katholischen Feldpastoral galt es allerdings primär, die Bedingungen der Möglichkeit für das ewige Überleben der Soldaten zu schaffen.

In der von Militärbischof Bjelik ausdrücklich als vorbildhaft bezeichneten, deshalb als „Feldseelsorge-Pastoralinstruktion“100 im „Pastoralblatt für die katholische k.u.k. Militär- und Marinegeistlichkeit“ veröffentlichten Artikel „Aufgaben des Feldseelsorgers“ von Feldkurat Johann Parsch werden als die „besonderen Ziele der Feldseelsorge“" genannt:

Die Vorbereitung des Soldaten auf den Tod im Gnadenstande; das ist wohl das wichtigste Ziel ... Ich könnte die ganze Feldseelsorge auf dieses Ziel einstellen: 1. entferntere Vorbereitung auf den Tod: Beicht, Kommunion, Predigt, Gottesdienst; 2. nähere Vorbereitung: Generalabsolution; 3. nächste Vorbereitung: letzte Oelung und heilige Wegzehrung. ... Eine bedeutende Seelsorgehilfe ist die Todesgefahr; diese macht die härtesten Herzen weich. ... Jedenfalls ... kann der Feldseelsorger mit der Todesgefahr als einer sehr tüchtigen Bundesgenossin rechnen.

Der Verfasser hatte zunächst nichts anderes getan, als die Kernfrage der zeitgenössischen christkatholischen Pastoral auf die Kriegssituation anzuwenden. Die klassische Katechismusfrage „Wozu sind wir auf Erden?“ und die Antwort „Um Gott zu lieben, ihm zu dienen und dadurch in den Himmel zu kommen“ formulierte die Perspektive auf ein Leben, das bei all seiner explizit gerechtfertigten Wertschätzung als Durchgangsphase zu gelten hatte, jenseits dessen Endes das ,ewige Leben' stehen konnte. Wie im zivilen Leben stellte die Kirche hierzu die vom Feldkuraten Parsch genannten Mittel und Wege bereit und gab Weisung für eine angemessene Lebensführung. Das von österreichisch-ungarischen Feldkuraten gern gebrauchte Predigtmotiv „Eine kleine Weile“ hatte eben jenes Endziel

99 Bei Plaut, Psychographie des Kriegers, S. 78 sind genannt: „Kruzifixe, Glücksklee, Glückpfennige, geweihte Münzen, auch Schuppen von Karpfen, Himmelsbriefe usw.“ Zu Einsiedeln vgl. Valentin Groebner, ,Soldatenfotos für die Schwarze Madonna“, in: ZIG 8 H. 2 (2014) S. 77-97.

100 Parsch, Aufgaben des Feldseelsorgers, S. 5. Das f. Zitat ebd., S. 4-5. 
zum Thema. ${ }^{101}$ Im Vergleich zum kurzen Leben auf Erden verblasste im Angesicht des ewigen Lebens der Schrecken des Todes, so jedenfalls die Intention.

Voraussetzung für das ewige Leben war es, sich zum Zeitpunkt des Todes im Gnadenstand zu befinden. Nicht die gemeinschaftliche Feier der Messe oder der Empfang des Altarsakraments bildeten das Zentrum katholischer Feldpastoral im Ersten Weltkrieg, sondern Beichte und Absolution. Idealerweise wäre es die Einzelbeichte gewesen, die den Gnadenstand der Kombattanten zu sichern hatte, und zwar so häufig wie nur möglich. Denn angesichts der besonderen Gefahren, die das Soldatenleben mit sich brachte wie etwa Fluchen, Diebstahl, Akte der Illoyalität oder jegliche Form der Unsittlichkeit war das ewige Leben noch gefährdeter als im zivilen Leben. Daher wurde ein besonderes Augenmerk auf Beichtgelegenheiten gerichtet, die in Ruhezeiten bei den Regimentern von Tausenden genutzt wurden, während die Spitäler andere Möglichkeiten boten. Bei Kampfeinsätzen war die Einzelbeichte meist unmöglich, zur Abhilfe wurde die Generalabsolution gegeben. So zog Feldkurat Parsch in seinem ersten Einsatz bei einem Angriff des Regiments im Juli 1915 mit Teilen desselben zum Dnjestr und erteilte die Absolution. „Immer wieder spricht er die Worte: ,Gehet nur ruhig in den Kampf! Wenn ihr auch fallet, ihr kommt alle in den Himmel!، “102

Die These, eben aus diesem Grund hätten sich katholische Feldgeistliche des Ersten Weltkriegs aller Nationen sich in Kampfsituationen besonders exponiert, ${ }^{103}$ dürfte in dieser Ausschließlichkeit nicht zutreffen. Es gab Militärgeistliche wie den österreichisch-ungarischen Feldkuraten Franz Josef Hämmerle oder den deutschen Feldgeistlichen Anton Konermann, die ihr Amt in dieser Weise ausübten. ${ }^{104}$ Wie sehr dies die ureigene Aufgabe eines Geistlichen war, zeigt auch der Bericht eines französischen Priesters. Im Frühjahr 1917 nahm er an einem Angriff teil und sah die eigenen Soldaten wie üblich in einem Hagel von Geschossen vor- und niedergehen. „Beim Anblick dieser unglücklichen Soldaten ... hat sich mein Arm instinktiv gehoben, und die Worte der Absolution haben meine Lippen verlassen. “105 In realistischer Einschätzung der Möglichkeit, eine beson-

101 „Eine kleine Weile irdisches Elend u. dann ewige Freude“. Feldkurat Viktor, Garnisonsseelsorge Bozen, Pastoralbericht April 1918. OeSta KA AFV Akten Ktn. 240. 102 Zeitschrift die 93er im Weltkrieg, Heft 36/37 vom 1.3.1936, S. 551. Zit. nach: Höslinger, Lebensweg, S. 27.

103 Vgl. Hassner, Religion on the Battlefield, S. 11-14. Hassner begründet die These mit den relativ höheren Todesraten katholischer britischer Feldgeistlicher im Vergleich zu den anderskonfessionellen.

104 Hämmerle wurde durch eine Granatexplosion am 20.1.1918 bei einem Versehgang an der Front getötet. Vgl. Lipusch, Militärseelsorge, S. 581-583. Der deutsche Feldgeistliche Anton Konermann, 6. Infanteriedivision, beschreibt eindrucksvoll, wie er an der Somme im feindlichen Feuer in einer Nacht 56-mal das Sterbesakrament spendet. Vgl. Bericht vom 2.11.1916. BA MA PH 32135.

105 Bericht des französischen Feldgeistlichen Duchet vom 10.6.1917, S. 5 f. Zit. nach 
ders große Zahl von Kombattanten zu absolvieren, hielten sich die meisten Geistlichen der Kampftruppen jedoch bei den frontnahen Verbandplätzen auf, was nicht unbedingt ungefährlicher sein musste.

\section{Opfer und Märtyrer}

Die Einforderung unbedingter Hingabe- und Opferbereitschaft der Soldaten gründete sich in der katholischen Feldpastoral des Ersten Weltkriegs primär auf argumentative Parallelisierungen mit Leiden, Sterben und Auferstehung Jesu Christi. In der Kriegszeit hatte die Konzentration auf den passiv leidenden und sich aktiv opfernden Christus eine doppelte Funktion. Zum einen hat sich gezeigt, dass selbst nach diesem nur scheinbar sinnlosen Leiden die Hoffnung auf ein ewiges Leben möglich ist. Zum anderen steht jeder, der sich wie Christus selbst für andere opfert, in der direkten Nachfolge Christi und wird entsprechend mit dem ewigen Leben vergolten. Kaum eine Stelle aus den Evangelien findet sich so häufig zitiert wie Joh. 15,13: „Es gibt keine größere Liebe, als wenn einer sein Leben für seine Freunde dahingibt.“

Die Betonung der Hingabe des Lebens aus ,Liebe“ konnte auf eine affektive Dimension katholischer Frömmigkeit des 19. Jahrhunderts aufbauen. Denn die Präsentation des Erlöserleidens in Wort, Schrift und Bild war eher entschärft und der Aspekt der Barmherzigkeit betont worden. ${ }^{106}$ Der Gottessohn war Gerichtsherr am Ende der Zeiten, in der Gegenwart bot er dem Sterbenden und dessen Angehörigen Trost. In der Verkündigung in der Heimat und an der Front wurde dies durchgängig akzentuiert, besonders an den geeigneten Stellen des Kirchenjahres wie den Kar- und Ostertagen, Weihnachten und dem zentralen katholischen Totengedenktag, an Allerseelen. In der Allerseelenpredigt vom 2. November 1914 betonte der Speyrer Bischof und stellvertretende Feldpropst der bayrischen Armee, Michael Faulhaber, den Charakter des Festes als „Tag des Trostes im Jahre der Trauer".${ }^{107}$ Forderten Gott, Kirche, Monarch und Nation in aller Strenge Treue und Opferbereitschaft ein, stand Jesus für Nachfolge im Leiden, erlösende Milde und ein Verständnis für Schwäche.

Annette Jantzen, Priester im Krieg. Elsässische und französisch-lothringische Feldgeistliche im Ersten Weltkrieg (=Veröffentlichungen der Kommission für Zeitgeschichte, Reihe B, Bd. 116), Paderborn u. a. 2010, S. 197.

106 Vgl. Andreas Holzem, „Personen der Überwelt“, in: Peter Dinzelbacher (Hrsg.), Handbuch der Religionsgeschichte im deutschsprachigen Raum, Bd. 5: 1750-1900, Paderborn u. a. 2007, S. 239-285, S. 262.

107 Michael Faulhaber, ,,Tröstet einander‘. Allerseelenpredigt 1914 im Dom zu Speyer und das Trostgebet", in: Dominik Schindler (Hrsg.), Faulhaber in Speyer. Predigten, Veröffentlichungen und Ansprachen der Bischofsjahre 1911-1917 (= Schriften des Diözesan-Archivs Speyer, Bd. 51), Speyer 2017, S. 85-100, S. 86. 
Der österreichisch-ungarische Militärbischof Bjelik betonte in seinen den Soldaten in den Sprachen der Monarchie verlesenen Weihnachtshirtenbriefen von 1914 und 1915 diesen Aspekt und verband ihn mit Realität wie Anforderungen des Krieges. Als „Nachfolger Christi ... durch Mangel und Entsagung härtester Art, Kälte und Schmerz, blutende Wunden und Todesmut" stehen die Soldaten nun bei „dem armen Kinde Jesu in der Krippe“. ${ }^{108}$ Im zweiten Kriegsjahr wurde auf ähnliche Weise die Gemeinschaft von Front und Heimat zu betonen gesucht, alle

nehmen wir unsere Zuflucht zur Krippe, zum göttlichen Jesuskinde. Der wetterharte Soldat draußen auf dem Vorposten im Feindesland, sowie der von Fieber durchglühte Krieger auf seinem Schmerzenslager im Spitale und die einsame Frau des Soldaten daheim mit ihrer Kinderschar, alle sind im Geist vereint an der Krippe des Heilandes. ${ }^{109}$

Die Konzentration auf Milde und das Kind in der Krippe wurden ergänzt, teilweise verdrängt durch eine Maskulinisierung katholischer Frömmigkeit. Das Bild „des martialisch gezeichneten, dem industrialisierten Krieg gewachsenen ,Isonzokriegers““110 findet sich im Weihnachtshirtenbrief Bjeliks 1917. Mit Blick auf anstehende Kämpfe - trotz der Niederlage des Zarenreichs und des Schlachtensieges gegen Italien - werden die Soldaten aufgefordert: „Dann steh fest im Glauben, sei männlich und stark! ... Wie ein Fels im tosenden und brandenden Weltmeer werden wir stehen ... Zäher Stahl, blanker Schild“"111. Christus war in den Worten eines Kuraten nicht das Kind in der Krippe oder der passiv Leidende am Kreuz, sondern der aktiv sein Los auf sich nehmende „Riesenkreuzträger von Golgotha". 112

Die aktivische Seite des Opfers der Kombattanten betonte ebenfalls die Interpretation des Soldatentods als Märtyrertod. ${ }^{113}$ In der Kriegszeit war diese

108 Emmerich Bjelik, „Weihnachtshirtenbrief 1914“, in: Pastoralblatt für die k.u.k. katholische Militär- und Marinegeistlichkeit 1916, Nr. 1, S. 3.

109 Weihnachtshirtenbrief 1915, in: Pastoralblatt für die k.u.k. katholische Militär- und Marinegeistlichkeit 1916, Nr. 1, S. 4-5, S. 4.

110 Christa Hämmerle, Heimat/Front. Geschlechtergeschichte/n des Ersten Weltkriegs in Österreich-Ungarn, Wien / Köln / Weimar 2014, S. 19.

111 Emmerich Bjelik, „Weihnachtsgruß an die Front“, in: Pastoralblatt für die k.u.k. katholische Militär- und Marinegeistlichkeit 1917, Nr. 1, S. 3-4, S. 4.

112 Diese vermutlich von Franz Josef Hämmerle, Feldkurat des k.u.k. Infanterieregiments 14 stammende Formulierung ist zitiert in einem Frontreisebericht des Linzer Bischofs Johannes Maria Gföllner. Linzer Diözesanblatt 63 (1917) S. 81-90, S. 83. Zur Frontreise Gföllners vgl. Thomas Schulte-Umberg, „Voll christlichen Opfersinnes“. Ein Beitrag zur Geschichte des Bistums Linz im Ersten Weltkrieg, in: NAGDL 20 (2015) S. $110-124$.

113 Für eine historische Kontextualisierung wäre in jedem Fall neben der Tradition der Blutzeugenschaft die Diffusion von religiösen und säkularen Topoi seit der Französischen 
Deutung nicht flächendeckend, aber gängig. In tröstender Absicht ließ ein preußischer Feldgeistlicher eine Benachrichtigung an die Angehörigen von Soldaten drucken, der sie des Märtyrerstatus des Toten versicherte und damit dessen unmittelbarer Aufnahme in den Himmel. ${ }^{114}$ In einer Allerseelenansprache im November 1915 auf dem Soldatenfriedhof von Nowy Poczajew (Wolhynien) versicherte ein Feldkurat, die „Worte der Kirche von ihren Blutzeugen, den hl. Märtyrern, gelten auch von dem gefallenen Krieger und sind der mildernde Balsam, welcher Trost und Linderung in die Herzen der betrübten Angehörigen der Gefallenen einflößt.“115

Das Thema Märtyrertod der Soldaten zog weite Kreise. In der zitierten Allerseelenpredigt Bischof Faulhabers aus dem Jahr 1914 rekurrierte dieser auf eine Stelle in der Summa Theologiae Thomas von Aquins und bestätigte, wir „dürfen ... den Soldaten, die in Gottes Namen, weil es Gottes Wille war, für die Rechte des Vaterlandes ihr Leben geopfert haben, in gewissem Sinn die Siegespalme eines Märtyrers aufs Grab legen.“116 Allerdings fügte er einschränkend hinzu, in ,einem Sinne freilich ist der Soldatentod kein Märtyrertod.“ Denn „es gibt so viel Staub auf der Landstraße des Lebens, und es ist so schwer, den Schild ganz blank zu halten." Es werde nicht alle Schuld und Strafe beseitigt, diese müsse noch im Fegefeuer gesühnt werden. Faulhaber nahm damit eine mittlere Position in einer Debatte ein, die zwischen dem belgischen Kardinal Mercier und dem französischen Kurienkardinal Billotte ausgetragen wurde. Während Mercier für einen Märtyrerstatus plädierte, wandte sich Billotte aus theologischen Gründen strikt dagegen, dabei warnte er eindringlich vor über den Krieg hinausreichenden Implikationen. ${ }^{117}$

Ein Märtyrerstatus konnte auch Priestern im Krieg zugesprochen werden. 1915 veröffentlichte ein französischer Autor unter dem Pseudonym René Gaëll das Buch „Les Soutanes sous la Mitraille“, ein rasch populär werdendes Buch, das ein Jahr später in englischer Übersetzung erschien. ${ }^{118}$ Das Buch zeigt die französischen Priester als Helden und Märtyrer eines christlichen, katholischen, anti-

Revolution zu bedenken. Für Osteuropa vgl. die Beiträge in Martin Schulze Wessel (Hrsg.), Nationalisierung der Religion und Sakralisierung der Nation im östlichen Europa (=Forschungen zur Geschichte und Kultur des östlichen Mitteleuropa, Bd. 27), Stuttgart 2006.

114 Vgl. Bericht Feldgeistlicher Joseph Kern, 11. Reserve-Divison, 26.7.1915. BA MA PH 32608.

115 Feldkurat Anton Dvořák, 29. Infanterietruppen-Division an AFV, 2.11.1915. OeSta KA AFV Akten Ktn. 223 mit dem Text der Predigt.

116 Michael Faulhaber, „Tröstet einander“. in Schindler (Hrsg.), Faulhaber in Speyer, S. 95, das f. Zitat S. 96.

117 Vgl. Ernst H. Kantorowicz, „Pro Patria Mori“, in Medieval Political Thought, in: AHR 56 (1951) S. 472-492, S. 472-473.

118 Vgl. René Gaëll, Les Soutanes sous la Mitraille, Paris 1915, das folgende S. 42, 51. 
protestantischen und patriotischen Krieges, die im Todeskampf mit den sakrilegischen deutschen Barbaren stehen. Der Sieg werde, so prophezeite der Autor, nur kommen durch freiwilliges Opfer und freiwilliges Leiden. Für den Märtyrerstatus und die Erlösung der Nation wäre dies entscheidend.

\section{Totenverwaltung}

Im Januar 1918 traf beim Apostolischen Feldvikariat in Wien ein Brief ein, der einen Aspekt des Kriegsalltags der Habsburgermonarchie repräsentiert, welcher bisher in der historischen Forschung allgemein wie in seinen Implikationen für die Rolle von Religion und Kirchen so gut wie nicht beachtet wurde. ${ }^{119}$ Die in einem Dorf im österreichischen Teil Schlesiens lebende, seit 9 Jahren verwitwete Verfasserin teilte mit, sie lebe in Elend und Hunger. Der jüngere ihrer beiden Söhne war im Mai 1915 in Galizien gefallen, der ältere als Offizier des k.u.k. InfanterieRegiments 20 „wahrscheinlich“ am 26.8.1917 an der Isonzo-Front. Mit diesem Datum sei die Zahlung des Lehrergehaltes ihres älteren Sohnes eingestellt worden, von dem sie seit Jahren gelebt habe, seitdem stehe sie nicht nur gänzlich ohne Mittel da, sondern müsse dessen Lebensversicherung noch weiter bezahlen. „Mitleid, Erbarmen ... ihr grosses Recht“ hoffe sie nun beim Feldvikariat zu finden, wo „bisher nur Unrecht ihr Lohn für Tapferkeit, Throntreue und junges Leben zweier ihrer Söhne" war. Auf dem Brief bestätigte der Ortsbürgermeister die Angaben und unterstützte die Bitte „kräftigst“.

Im Brief teilte die Verfasserin ein Schreiben des Regimentskommandos vom 9.10.1917 mit, in dem es hieß:

Nach zweimaliger Ausfrage über die Todeszeugen des angeblich gefallenen ... wurde von einem Zeugen folgendes mitgeteilt: ,Ich habe zwar gesehen persönlich, wie H. Ob. Lt. Zafraniec die Kugel in den Hals bekam und gleich danach zusammenstürzte, doch habe ich ihn nicht näher untersuchen können.‘ ... Da der verwundete ... in Feindeshand geblieben, kann nicht konstatiert werden, ob er lebt oder gestorben ist; infolgedessen muß er als ,vermißt' gelten.7.10.1917 Vykonžil Fkt. ${ }^{120}$

Obzwar nach dieser Aussage der Tod ihres Sohnes nicht als sicher gelten konnte, musste seine Mutter sich in ihrer Notlage um eine amtliche Todesfeststellung bemühen, ohne die in ihrem Fall weder die Lehrerpension wieder noch die von

119 Marie Zafranowiec, Witwe an Apostolisches Feldvikariat, Petrowitz bei Freistadt, 10.1.1918. OeStA KA AFV Akten Ktn. 180. - Die im Folgenden nur knapp angedeuteten Bestimmungen zur Matrikenführung werden genannt bei Thomas Reichl, Das Kriegsgräberwesen Österreich-Ungarns im Weltkrieg und die Obsorge in der Republik Österreich. Das Wirken des Österreichischen Schwarzen Kreuzes in der Zwischenkriegszeit, Phil. Diss, Wien 2007, S. 55-79.

120 Der Name lautet wohl richtig: Feldkurat Anton Vystonžil. 
ihm abgeschlossene Lebensversicherung überhaupt ausbezahlt wurde. Solche Folgen eines nicht amtlich bestätigten Todes eines Soldaten dürften Millionen Menschen in den kriegführenden Nationen getroffen haben. ${ }^{121}$ Doch anders als etwa im Deutschen Reich, in Frankreich und in Großbritannien war in ÖsterreichUngarn die Geistlichkeit unmittelbar dafür zuständig.

Die Anfänge der Personenstandsführung liegen, das ist bekannt, in der Führung von Personenstandsbüchern (Matriken) durch die Geistlichkeit. ${ }^{122}$ Die Verzeichnung von Taufen, Eheschließungen und Verstorbenen diente nicht nur kirchlichen Zwecken, sondern war Grundlage für die Erfassung der auf einem Territorium lebenden Menschen. Bis ins 19. Jahrhundert waren die Kirchen in Europa aufgrund ihrer in die Fläche hineinreichenden Organisation in dieser Hinsicht unentbehrlich. Im Zuge der Dynamik des Ausbaus eines effektiveren Staates wie der Staat-Kirche-Konflikte seit der Aufklärung wurde die Personenstandsführung aber nach und nach von staatlicher Seite übernommen. In Frankreich begann dies mit der Revolution der 1790er Jahre, in England und Wales war die Einführung des General Register Office 1837 wichtig, im Deutschen Reich die Einführung von Standesämtern seit $1870 .{ }^{123}$ Anders war die Situation in der Habsburgermonarchie. Im ungarischen Kulturkampf der 1890er Jahre war für den ungarischen Reichsteil zwar die zivile Personenstandsführung eingeführt worden, im österreichischen Reichsteil war jedoch weiterhin die Geistlichkeit zuständig. ${ }^{124}$ Das galt im Weltkrieg für die Militärgeistlichkeit, wobei dem Anschein nach anders als im zivilen Raum die ,ungarischen' Militärgeistlichen ebenfalls für die Personenstandsführung der Militärs zuständig waren. Der zitierte Brief der Witwe ist daher weniger als Bitte um Protektion denn als Wendung an eine Institution zu verstehen, von der sie sich mit Recht eine Abhilfe versprechen konnte. Das Apostolische Feldvikariat war im Krieg die Zentrale für

121 Vgl. die Bemerkung bei Stéphane Audoin-Rouzeau, „Corps perdus, corps retrouvés: Trois exemples de deuils de guerre“, in: Annales 55 (2000) S. 47-71, S. 48, nur die Hälfte der französischen Kriegstoten habe zunächst verlässlich identifiziert werden können. Allgemein spielte neben den durch Kriegsumstände verursachten Ungewissheiten eine Rolle, dass das Schicksal von vielen Gefangenen ungewiss war.

$122 \mathrm{Zu}$ den Militärmatriken der Monarchie vgl. Christoph Tepperberg, Die Militärmatriken im Kriegsarchiv Wien 1633-1938, in: MÖSTA 49 (2001) S. 59-90.

123 Vgl. Gérard Noiriel, „L'identification des citoyens. Naissance de l'état civil republicain“, in: Genèses 13 (1992) S. 3-28; Edward Higgs, Life, death and statistics: civil registration, censuses and the work of the General Register Office, 1837-1952, Hatfield 2004. Seit dem Bismarck'schen Kulturkampf ist nur noch die staatliche Beurkundung von Geburt, Heirat und Tod rechtsgültig. Vgl. Gesetz über die Beurkundung des Personenstandes und die Eheschließung, in: Deutsches Reichsgesetzblatt 1875, Nr. 4, S. 23-40.

124 Moritz Csáky, „Die römisch-katholische Kirche in Ungarn“, in: Helmut Rumpler / Adam Wandruska (Hrsg.), Die Habsburgermonarchie 1848-1918, Bd. IV: Die Konfessionen, Wien 1985, S. 248-331, S. 297-299. 
die Standesführung von mindestens $75 \%$ der etwa 1,5 Millionen toten österreichisch-ungarischen Soldaten. ${ }^{125}$

Nach den Bestimmungen zur Standesführung im Krieg war für die Matrikulierung eines Soldaten die Bestätigung von zwei Zeugen des Todesfalls auf dem Legitimationsblatt des Soldaten erforderlich. Dieses vom Soldaten selbst mit einem Bleistift auszufüllende Blatt war in einer mit einem Band in der rechten Hosentasche befestigten Metallkapsel mit sich zu tragen. ${ }^{126}$ Schon allein dies begünstigte zahllose Fehler, so wenn etwa statt Blei die Eintragungen mit Tinte vorgenommen wurden, diese nicht vollständig oder unleserlich waren, ein Soldat bei Alarm in der Eile die Hose eines anderen Soldaten anzog und im Kampf starb, bei Beerdigungen den Soldaten die Legitimationsblätter nicht abgenommen wurden und anderes mehr. ${ }^{127}$ Entscheidend für die Matrikulierung und in Folge die Ausstellung eines amtlichen Totenscheins war die Unterschrift eines Feldkuraten, die im Prinzip nur erfolgen konnte, wenn es die Unterschrift der zwei Zeugen gab. Ausnahmen von diesem Prinzip und im Kriegsverlauf mildere Auslegungen der Vorschriften gab es. Dies änderte aber nichts an der zentralen Rolle der Militärgeistlichkeit, die sich mit den enormen Schwierigkeiten der Standesführung in diesem Krieg konfrontiert sah.

Bei der Matrikulierung von Toten auf dem Schlachtfeld und in den Spitälern waren die Feldkuraten auf die Mitwirkung der Begehungs- und Begräbniskommandos sowie der Militärärzte angewiesen. Angesichts der Vielzahl der Leichen, deren Zustand und ihrer manchmal rohen Beseitigung war hier reichlich Raum für Fehler, die sich zum Nachteil der Standesführung und damit der Hinterbliebenen auswirkte. ${ }^{128}$ Letztere wandten sich in zahlreichen Briefen an Regimentskommanden, Spitäler, Feldkuraten, Ministerien, Feldsuperiorate und nicht zuletzt an das Apostolische Feldvikariat in Wien, sei es auch nur, um sich Gewissheit zu verschaffen, sei es, um Rechtsfolgen zu klären. ${ }^{129}$ Wenn es möglich war, wurde

$125 \mathrm{Zu}$ den Verlustzahlen vgl. Rüdiger Overmans, „Kriegsverluste“, in: Gerhard Hirschfeld u. a. (Hrsg.), Enzyklopädie Erster Weltkrieg, erw. u. aktualis. Studienausgabe, Paderborn u. a. 2009, 663-666, S. 664-665 (Tabelle Kriegsverluste). - Die Angabe 75 \% entspricht dem römisch- und griechisch-katholischen Konfessionsanteil an der Gesamtbevölkerung.

126 Beschreibung in Bjelik, Handbuch, S. 239.

127 Solche und ähnliche Fälle finden sich regelmäßig in den Tageszeitungen der Monarchie.

128 Vgl. rückblickend z.B. Kooperator Wilhelm Binder, Divisionspfarrer a.D., an Bischöfliches Ordinariat Linz, Traiskirchen 25.6.1919. Diözesanarchiv Linz CA 9/11 I/13 a9.

129 Vgl. z. B. Rechtsanwalt Hugo Roth an KM, Prag 19.6.1915. OeSta KM Abt. 9 Akten 1915 Ktn. 766, 10-296-2 mit der Bitte um Auskunft zum Verbleib des Ehegatten von Alice Kisch, Prag; Franz Jeschek an KM, Spiegelhütte 30.7.1916 mit der Frage, ob es sich in der Nachricht eines Feldkuraten über den Tod eines Sohnes um den ersten oder 
ebenso die persönliche Vorsprache gesucht. In den Räumen des Feldvikariats und der genannten Behörden versammelten sich während der Geschäftszeiten alsbald täglich Hunderte Hilfesuchende, die manchmal nicht einsehen wollten, warum auf den öffentlichen Verlustlisten jemand als tot aufgeführt war, er aber nicht als solcher matrikuliert wurde.

Selbst wenn ein Soldat standesgeführt war, konnte die Ausstellung eines Totenscheins unmöglich sein. Die Matrikulierung litt neben den - hier nur angedeuteten - praktischen Schwierigkeiten während des Krieges an einem elementaren systemischen Mangel. ${ }^{130}$ Für die Verzeichnung der Toten zuständig waren bei Truppenteilen eigentlich die Feldkuraten der Konfession, der der Tote angehörte, bzw. der Kurat des Spitals, in dem jemand verstarb. ${ }^{131}$ Die Fälle waren nach Verzeichnung an die zuständigen Ergänzungskommanden und das Feldvikariat in Wien zu leiten und sollten dort bei Nachfrage aufzufinden sein. In zahlreichen Fällen funktionierte dieses Verfahren auch, in zahlreichen anderen freilich nicht. Unter den Bedingungen des Kriegs kam es - wohl selbstverständlich - vor, dass Geistliche die von ihnen aufgefundenen Toten aus reiner Notwendigkeit protokollierten, obwohl diese nicht ihrer Einheit angehörten oder nicht in ,ihrem‘ Spital starben, z. B. ein dem 5. Bataillon des Infanterieregiments 64 angehöriger Soldat vom Feldkuraten des benachbarten 1. Bataillons des Infanterieregiments 63 standesgeführt wurde. Ein solcher Toter war nicht als verzeichnet auffindbar, da die Suche nach ihm nur über die von ihm bekannte Einheit oder das Spital erfolgen konnte - ein zentrales alphabetisches Namensregister fehlte. Teilweise lesen sich die in den Akten der Wiener Ministerien und des Militärbischofs verzeichneten Suchbewegungen wie eine sinnlose, sich selbst zersetzende Aktion. Gerade auf diese Weise war die habsburgische Feldgeistlichkeit Teil jener bürokratischen Maschinerie, deren (Selbst-)Zerstörungskräfte Franz Kafka im Herbst 1914 ahnungsvoll beschrieben hatte. ${ }^{132}$

\footnotetext{
zweiten Sohn handle, die beide wohl gefallen seien. OeSta KM Abt. 9 Akten 1916 Ktn. 980, 10-9-102; Stefanie Ostiadal an KM, Siegmar 8. 6.1917 in Ungewißheit über das Schicksal ihres Mannes seit November 1914 und der Bitte um nunmehrige Ausstellung eines Totenscheins. Die Bitte wurde abschlägig beschieden. OeSta KM Abt. 9 Akten 1917 Ktn. 1167, 10-9-14.

130 Vgl. zum folgenden Denkschrift vom 6.9.1919. OeSta KA AFV Akten 166 o. Nr. 131 In den Spitälern wurde konfessionsunabhängig matrikuliert.

132 Vgl. Franz Kafka, In der Strafkolonie, Berlin 1995, im Freundeskreis vorgetragen im Dezember 1914 wenige Wochen nach der Niederschrift, Erstdruck 1919.
} 


\section{Die lange Dauer}

Unter den Bedingungen des Ersten Weltkrieges nimmt es kaum Wunder, wenn die Bindekraft von Religion nachließ und diese von zahlreichen Menschen individuell wie kollektiv in Frage gestellt wurde. Die - zeitgenössisch wie auch immer begründete - Behauptung, dieses Geschehen wäre kompatibel mit transzendenten Absichten, konnte auf Dauer wohl eher nicht als sinnhaft vermittelt werden. Jaroslav Hašeks Kunstfigur Otto Katz, Karl Kraus' Anton Allmer, George Grosz' Zeichnungen stellen mit künstlerischen Mitteln gefertigte, treffende kritische Kennzeichnungen von Indienstnahme und Erscheinungsformen von Religion im Ersten Weltkrieg dar. Dennoch ist die langfristige Entwicklung von Religiosität in Europa zunächst erstaunlich stabil geblieben. Die „Urkatastrophe des 20. Jahrhunderts" (George Kennan) zog kurzfristig keinen deutlichen Einbruch christlich-konfessionell gebundener Religiosität nach sich.

Ebenso wenig änderte sich in der Zwischenkriegszeit das Verhältnis jedenfalls der katholischen Kirche und zahlreicher Katholiken zum Krieg grundlegend. ${ }^{133}$ Selbst unter den Bedingungen des NS-Regimes blieb die Kriegsdienstverweigerung des oberösterreichischen Bauern Franz Jägerstätter singulär. Erst die kirchlich-christliche Absage an den Krieg insbesondere seit den 1960er Jahren ließ die Beförderung von und Partizipation in früheren Kriegen als Sünde gegen das Wesen des Christentums erscheinen, ein Zustand, der nun - zum Glück vergangen war. Die Konsequenz ist ein tiefsitzendes „Problem der Kriegsverdrängung ${ }^{\text {“134 }}$ bei Kirchen und Christen im deutschsprachigen Raum. Krieg ist besten- wie schlimmstenfalls ein zutiefst amoralisches, den eigenen Gedankenwelten und Praktiken konträres Geschehen. Das ist wohl zu begrüßen - für ein historisch informiertes Verstehen von Vergangenheit (und Gegenwart) wäre es allerdings wenig hilfreich.

Die Darstellung von Allgemeinheiten wie Besonderheiten katholischer österreichisch-ungarischer Feldpastoral im Ersten Weltkrieg sollte zeigen, wie unter den Bedingungen dieses Krieges Religion und katholische Konfession für die Befestigung der Kriegsmoral von Kombattanten effektiv sein konnten. Katholische Feldpastoral gab durch die vermittelten Normen und ihre Praktiken der

133 Als Ausnahme neben dem „Friedensbund deutscher Katholiken“ ist zu nennen die geänderte Einstellung des Münchener Erzbischofs Faulhaber Anfang der 1930er Jahre. Zu diesem vgl. Karl-Joseph Hummel / Christoph Kösters, „Zur Einführung“, in: dies. (Hrsg.), Kirche, Krieg und Katholiken. Geschichte und Gedächtnis im 20. Jahrhundert, Freiburg/Br. 2014, S. 7-20, S. 7-8.

134 Die bei Hans Joas / Wolfgang Knöbl, Kriegsverdrängung. Ein Problem in der Geschichte der Sozialtheorie, Frankfurt am Main 2008 für den Liberalismus benannte Perspektive, seit der Aufklärung seien ,verallgemeinernd ... ganz besonders Kriege als Relikte einer untergehenden Epoche“ (S. 13) erschienen, ließe sich sicherlich auf das Bewusstsein vieler Christen jedenfalls in Deutschland seit den 1960er Jahren übertragen. 
Strukturierung vom Raum, Zeit und Kollektiv eine Antwort auf die Frage, warum dieses Geschehen über längere Dauer sinnvollerweise überhaupt auszuhalten sei. Die katholischen Militärgeistlichen standen in Amt und Person für diese motivierende Funktion von Religion ein, auch und gerade durch den Krieg relativierende Botschaften und Handlungen. Die katholische habsburgische Feldpastoral stellt keine Ausnahme dar, wobei ihre Effektivität anders als bisher geschehen nur in jenem Gefüge zu verstehen und $\mathrm{zu}$ analysieren ist, wie es hier skizziert wurde.

\section{Literaturverzeichnis}

Achleitner, Wilhelm, Gott im Krieg. Die Theologie der österreichischen Bischöfe in den Hirtenbriefen zum Ersten Weltkrieg, Wien / Köln / Weimar 1997.

Afflerbach, Holger, „Wenn man nicht in Allem, auch in dem Schwersten Gottes Hand erkennen will, ist man verloren", in: ZIG 8 H. 2 (2014) S. 35-36.

Albert, Franz, „Die katholische Seelsorge“, in: Max Schwarte, Der große Krieg 1914 1918. Bd. 10: Die Organisationen der Kriegführung, 3. Teil, Leipzig u. a. 1923, S. $221-$ 243.

Albert, Franz, Handbuch für die katholischen Feldgeistlichen des preußischen Heeres, Wilna 1918.

Altrichter, Friedrich, Die seelischen Kräfte des deutschen Heeres im Frieden und im Weltkriege, Berlin 1933.

Ardant le Picq, Charles, Études sur le Combat, Paris 1880.

Arnold, Matthieu / Dingel, Irene (Hrsg.), Predigt im Ersten Weltkrieg. La prédication durant la „Grande Guerre“ (= Veröffentlichungen des Instituts für Europäische Geschichte, Bd. 109), Göttingen 2017.

Artikel „Joeppen“ in: Brandt, Hans Jürgen / Häger, Peter (Hrsg.), Biographisches Lexikon der Katholischen Militärseelsorge Deutschlands 1848-1945, Paderborn 2002, S. 369-371.

Audoin-Rouzeau, Stéphane, „Corps perdus, corps retrouvés: Trois exemples de deuils de guerre“, in: Annales 55 (2000) S. 47-71.

Ayako Bennette, Rebekka, Rezension von Catholicism and Great War, in: CEH 49 (2016) S. 276-277.

Bauerkämper, Arnd / Julien, Elise (Hrsg.), Durchhalten! Krieg und Gesellschaft im Vergleich 1914-1918, Göttingen 2010.

Bellamy, Alex J., Just wars: from Cicero to Iraq, Cambridge / Malden 2006.

Beyrau, Dietrich, „Projektionen, Imaginationen und Visionen. Die orthodoxe Militärgeistlichkeit im Einsatz für Glauben, Zar und Vaterland 1914-1917“, in: JGO 52 (2004), S.402-420.

Bjelik, Emmerich, „Weihnachtsgruß an die Front“, in: Pastoralblatt für die k.u.k. katholische Militär- und Marinegeistlichkeit 1917, Nr. 1, S. 3-4.

Bjelik, Emerich, „Weihnachtshirtenbrief 1915“, in: Pastoralblatt für die k.u.k. katholische Militär- und Marinegeistlichkeit 1916, Nr. 1, S. 4-5. 
Bjelik, Emmerich, „Weihnachtshirtenbrief 1914“, in: Pastoralblatt für die k.u.k. katholische Militär- und Marinegeistlichkeit 1916, Nr. 1, S. 3.

Bjelik, Emmerich, Handbuch für die k.u.k. katholische Militärgeistlichkeit, Wien 1905.

Blaskovic, Pero, Mit den Bosniaken im Weltkrieg. Auszüge aus „Sa Bosnjacima U Svejtskom Ratu“, Wien 2001.

Boniface, Xavier, Histoire religieuse de la Grande Guerre, Paris 2014.

Boniface, Xavier, L'aumônerie militaire française, 1914-1962, Paris 2001.

Brendle, Franz / Schindling, Anton (Hrsg.), Geistliche im Krieg, Münster 2009.

Broucek, Peter (Hrsg.), Ein General im Zwielicht: die Erinnerungen Edmund Glaises von Horstenau. Bd. 1: K. u. k. Generalstabsoffizier und Historiker (= Veröffentlichungen der Kommission für Neuere Geschichte Österreichs, Bd. 67), Wien 1980.

Cole, Lawrence / Hämmerle, Christa / Scheutz, Martin, „Glanz - Gewalt - Gehorsam. Traditionen und Perspektiven der Militärgeschichtsschreibung zur Habsburgermonarchie“, in: dies. (Hrsg.), Glanz-Gewalt-Gehorsam: Militär und Gesellschaft in der Habsburgermonarchie (1800 bis 1918) (=Frieden und Krieg. Beiträge zur historischen Friedensforschung, Bd. 18), Essen 2011, S. 13-28.

Csáky, Moritz, „Die römisch-katholische Kirche in Ungarn“, in: Rumpler, Helmut / Wandruska, Adam (Hrsg.), Die Habsburgermonarchie 1848-1918, Bd. IV: Die Konfessionen, Wien 1985, S. 248-331.

Demy, Timothy J., „Military Chaplains in the First World War“, in: Heath, Gordon L. (Hrsg.), American Churches in the First World War, Eugene (OR) 2016, S. 95-102.

Dienstbuch A-16f. Bestimmungen für die Militärseelsorge und die Matrikelführung im Kriege, Wien 1914.

Egger, Michael, Rezension von Catholicism and Great War, in: HZ 304 (2017) S. 258-259.

Faulhaber, Michael, ,,Tröstet einander‘. Allerseelenpredigt 1914 im Dom zu Speyer und das Trostgebet", in: Schindler, Dominik (Hrsg.), Faulhaber in Speyer. Predigten, Veröffentlichungen und Ansprachen der Bischofsjahre 1911-1917 (= Schriften des Diözesan-Archivs Speyer, Bd. 51), Speyer 2017, S. 85-100.

Faulkner-Rossi, Lauren, Rezension von Catholicism and Great War, in: AHR 122 (2017) S. 947-948.

Foch, Ferdinand, Des principes de la guerre. Conférences faites en 1900 à l'École supérieure de guerre, Paris 1911.

Frontreisebericht des Linzer Bischofs Johannes Maria Gföllner. Linzer Diözesanblatt 63 (1917) S. 81-90.

Gaëll, René, Les Soutanes sous la Mitraille, Paris 1915.

Gramsci, Antonio, Passato e Presente (= Opero di Antonio Gramsci, 7), Mailand 1954.

Greschat, Martin, Der Erste Weltkrieg und die Christenheit: Ein globaler Überblick, Stuttgart, 2013.

Groebner, Valentin, „Soldatenfotos für die Schwarze Madonna“, in: ZIG 8 H. 2 (2014) S. 77-97.

Grosz, George, Hintergrund. 17 Zeichnungen zur Aufführung des „Schwejk“ in der Piscator-Bühne, Berlin 1928.

Halik, Tomáš, Geduld mit Gott. Die Geschichte von Zachäus heute, Freiburg im Breisgau 2010.

Ham, Claudia, „Von den Anfängen der Militärseelsorge bis zur Liquidierung des Apostolischen Feldvikariates im Jahr 1918“, in: Gröger, Roman-Hans / Ham, Clau- 
Thomas Schulte-Umberg

dia / Sammer, Alfred, Zwischen Himmel und Erde. Militärseelsorge in Österreich, Graz / Wien / Köln 2011, S. 13-98.

Hämmerle, Christa, Heimat/Front. Geschlechtergeschichte/n des Ersten Weltkriegs in Österreich-Ungarn, Wien / Köln / Weimar 2014.

Hašek, Jaroslav, Die Abenteuer des guten Soldaten Šveyk im Weltkrieg, Stuttgart 2014. Hassner, Ron E., Religion on the Battlefield, Ithaca 2016.

Healy, Maureen, Vienna and the Fall of the Habsburg Empire: Total War and Everyday Life in World War I, Cambridge 2007.

Higgs, Edward, Life, death and statistics: civil registration, censuses and the work of the General Register Office, 1837-1952, Hatfield 2004.

Hirschfeld, Magnus, Sittengeschichte des Weltkriegs, Wien 1930.

Hochedlinger, Michael, „Kleine Quellenkunde zur österreichischen Militärgeschichte 1800-1914“, in: Cole, Laurence / Hämmerle, Christa / Scheutz, Martin (Hrsg.), Glanz - Gewalt - Gehorsam: Militär und Gesellschaft in der Habsburgermonarchie (1800 bis 1918) (= Frieden und Krieg. Beiträge zur historischen Friedensforschung, Bd. 18), Essen 2011, S. 387-410.

Holzem, Andreas, „Personen der Überwelt“, in: Dinzelbacher, Peter (Hrsg.), Handbuch der Religionsgeschichte im deutschsprachigen Raum, Bd. 5:1750-1900, Paderborn u. a. 2007, S. 239-285.

Höslinger, Norbert, „Der Lebensweg von Pius Parsch“, in: Höslinger, Norbert / MaasEwerd, Theodor (Hrsg.), Mit sanfter Zähigkeit: Pius Parsch und die biblisch-liturgische Erneuerung (=Schriften des Pius-Parsch-Instituts Klosterneuburg Bd. 4), S. 13 78.

Hötzendorf, Franz Conrad von, Aus meiner Dienstzeit. 1906-1918, Bd. 4, Wien 1923.

Houlihan, Patrick J., Catholicism and the Great War: Religion and Everyday Life in Germany and Austria-Hungary, 1914-1922, Cambridge 2015.

Houlihan, Patrick J., Clergy in the Trenches. Catholic Military Chaplains of AustriaHungary and Germany in the First World War, Phil. Diss., Chicago 2011.

Hummel, Karl-Joseph / Kösters, Christoph, „Zur Einführung“, in: dies. (Hrsg.), Kirche, Krieg und Katholiken. Geschichte und Gedächtnis im 20. Jahrhundert, Freiburg im Breisgau 2014, S. 7-20.

Jantzen, Annette, Priester im Krieg. Elsässische und französisch-lothringische Feldgeistliche im Ersten Weltkrieg (=Veröffentlichungen der Kommission für Zeitgeschichte, Reihe B, Bd. 116), Paderborn u. a. 2010.

Joas, Hans / Knöbl, Wolfgang, Kriegsverdrängung. Ein Problem in der Geschichte der Sozialtheorie, Frankfurt am Main 2008.

Joly, Wolfgang, Standschützen. Die Tiroler und Vorarlberger Standschützen-Formationen im Ersten Weltkrieg. Organisation und Einsatz (= Schlern-Schriften, Bd. 303), Innsbruck 1998.

Kafka, Franz, In der Strafkolonie, Berlin 1995 [Erstdruck 1919].

Kallhoff, Angela / Schulte-Umberg, Thomas, „Die Wende zum Soldaten und Fragen der Kriegsmoral“, in: DZPhil 65 (2017) S. 762-780.

Kallhoff, Angela / Schulte-Umberg, Thomas, „The Committed Soldier: Religion as a Necessary Supplement to a Moral Theory of Warfare“, in: Politics, Religion \& Ideology 16 (2015) S. 434-448. 
Kantorowicz, Ernst H., „,Pro Patria Mori‘, in Medieval Political Thought“, in: AHR 56 (1951) S. 472-492.

Katholische militärkirchliche Dienstordnung mit Ausführungsbestimmungen, Berlin 1902.

Keegan, John, The Face of Battle, New York, 1976.

King, Anthony, The Combat Soldier: Infantry Tactics and Cohesion in the Twentieth and Twenty-First Centuries, Oxford 2013.

Klieber, Rupert, Jüdische - christliche-muslimische Lebenswelten der Donaumonarchie 1848-1918, Wien 2010.

Kramer, Alan, Dynamic of Destruction. Culture and Mass Killing in the First World War, Oxford 2007.

Kraus, Karl, Die letzten Tage der Menschheit. Tragödie in fünf Akten mit Vorspiel und Epilog, Frankfurt am Main 1986.

Kretschmann, Carsten, „,Der Herr sei mit Euch, Ihr braven Krieger‘. Sakralisierungsstrategien im Kontext des Ersten Weltkriegs“, in: Hummel, Karl-Joseph / Kösters, Christoph (Hrsg.), Kirche, Krieg und Katholiken. Geschichte und Gedächtnis im 20. Jahrhundert, Freiburg / Basel / Wien 2014, S. 50-66.

Kronenbitter, Günter, „Krieg im Frieden“. Die Führung der k.u.k. Armee und ÖsterreichUngarns Großmachtpolitik 1906-1914, München 2003.

Ladurner-Parthanes, Matthias, Kriegstagebuch eines Kaiserjägers, Bozen 1996.

Lätzel, Martin, Die Katholische Kirche im Ersten Weltkrieg: Zwischen Nationalismus und Friedenswillen, Regensburg 2014.

Leconte, Jacques-Robert, L'Aumônerie Militaire Belge, Brüssel 1966.

Lein, Richard, Pflichterfüllung oder Hochverrat? Die tschechischen Soldaten ÖsterreichUngarns im Ersten Weltkrieg (= Europa Orientalis, Bd. 9), Münster u. a. 2011.

Lipusch, Viktor, Österreich-Ungarns katholische Militärseelsorge im Weltkriege, Wien 1938.

Lussu, Emilio, Un Anno sull' Altopiano, Turin 1999.

Melichar, Peter / Mejstrik, Alexander, „Die bewaffnete Macht“, in; Rumpler, Helmut / Urbanitsch, Peter (Hrsg.), Die Habsburgermonarchie 1848-1918, Bd. IX/2: Von der Stände zur Klassengesellschaft, Wien 2010, S. 1263-1326.

Mittermaier, Johann, Die Schrecken des Krieges. Erinnerungen eines Südtiroler Kaiserjägers aus dem 1. Weltkrieg, Brixen 2005.

Morozzo Della Rocca, Roberto, La fede e la guerra. Cappellani militari e preti soldati 1915-1919, Udine 2015.

Müller, Carl Werner (Hrsg.), „Verzicht auf Revanche“: Das Kriegstagebuch 1914/18 des Divisionspfarrers der Landauer Garnison Dr. Anton Foohs (= Veröffentlichungen der Pfälzischen Gesellschaft zur Förderung der Wissenschaften, Bd. 108), Speyer 2010.

Neugebauer, Rosa, „George Grosz und sein Verhältnis zu Militarismus und Krieg“, in: Harth, Dietrich (Hrsg.), Pazifismus zwischen den Weltkriegen: Deutsche Schriftsteller und Künstler gegen Krieg und Militarismus, 1918-1933, Heidelberg 1985, S. 147-164.

Noiriel, Gérard, „L'identification des citoyens. Naissance de l'état civil republicain“, in: Genèses 13 (1992) S. 3-28.

Osterkamp, Jana / Schulze Wessel, Martin, ,Texturen von Loyalität. Überlegungen zu einem analytischen Begriff“, in: $G G 42$ (2016) S. 553-573. 
Overmans, Rüdiger, „Kriegsverluste“, in: Hirschfeld, Gerhard u.a. (Hrsg.), Enzyklopädie Erster Weltkrieg, erw. u. aktualis. Studienausgabe, Paderborn u. a. 2009, 663-666.

Parsch, Johann, „Aufgaben des Feldseelsorgers an der Front“, in: Pastoralblatt für die k.u.k. Militär- und Marinegeistlichkeit 1916 Nr. 2, S. 3-17.

Plaut, Paul, „Psychographie des Kriegers“, in: Stern, Wilhelm / Lipmann, Otto (Hrsg.), Beihefte zur Zeitschrift für angewandte Psychologie, Bd. 20, Leipzig 1920, S. 1-123.

Rauchensteiner, Manfried, Der Erste Weltkrieg und das Ende der Habsburgermonarchie 1914-1918, Wien 2013.

Reichl, Thomas, Das Kriegsgräberwesen Österreich-Ungarns im Weltkrieg und die Obsorge in der Republik Österreich. Das Wirken des Österreichischen Schwarzen Kreuzes in der Zwischenkriegszeit, Phil. Diss, Wien 2007.

Ruhmesblätter der k.u.k. Militär- und Marinegeistlichkeit aus dem Weltkrieg 1914-17, Wien 1917.

Rumpler, Helmut / Wandruszka, Adam (Hrsg.), Die Habsburgermonarchie 1848-1918. Bd. XI: Die Habsburgermonarchie und der Erste Weltkrieg, Teilbd. 2. Weltkriegsstatistik Österreich-Ungarn 1914-1918: Bevölkerungsbewegung, Kriegstote, Kriegswirtschaft, Wien 2014.

Rutte, Volker (Hrsg.), Die Kriegstagebücher des Franz Matthias Hartinger, Offiziersstellvertreter im k.k. Landsturm-Infanterie-Regiment Laibach No. 27, Graz 2012.

Schmitz, Martin, „Als ob die Welt aus den Fugen ginge“. Kriegserfahrungen österreichisch-ungarischer Offiziere 1914-1918 (= Krieg in der Geschichte, Bd. 86), Paderborn u. a. 2016.

Schneider, Constantin, Die Kriegserinnerungen.1914-1919, hg. von Oskar Dohle (=Veröffentlichungen der Kommission für Neuere Geschichte Österreichs, Bd. 95), Wien 2003.

Schulte-Umberg, Thomas, „,Voll christlichen Opfersinnes‘. Ein Beitrag zur Geschichte des Bistums Linz im Ersten Weltkrieg“, in: NAGDL 20 (2015) S. 110-124.

Schulte-Umberg, Thomas, „Religion im Ersten Weltkrieg“, erscheint in: ThRv 114 (2018).

Schulte-Umberg, Thomas, Kriegsmoral und Religion. Kriegserfahrungen in der katholischen Feldpastoral Österreich-Ungarns und des Deutschen Reichs im Ersten Weltkrieg, in Vorbereitung.

Schulze Wessel, Martin (Hrsg.), Nationalisierung der Religion und Sakralisierung der Nation im östlichen Europa (= Forschungen zur Geschichte und Kultur des östlichen Mitteleuropa, Bd. 27), Stuttgart 2006.

Sebag-Montefiore, Hugh, Somme: Into the Breach, Cambridge (Mass.) 2016.

Shay, Jonathan, Achilles in Vietnam. Combat Trauma and the Undoing of Character, New York 1994.

Shay, Michael E., Sky Pilots: The Yankee Division Chaplains in World War I, Columbia 2014.

Snape, Michael, „The Great War“, in: McLeod, Hugh (Hrsg.), The Cambridge History of Christianity Vol. 9: World Christianities c. 1914-c. 2000, Cambridge 2006.

Snape, Michael, God and the British Soldier: Religion and the British Army in the First and Second World Wars, London / New York 2005.

Stachelbeck, Christian, Deutschlands Heer und Marine im Ersten Weltkrieg, Paderborn u. a. 2013. 
Tepperberg, Christoph, „Die Militärmatriken im Kriegsarchiv Wien 1633-1938“, in: MÖSTA 49 (2001) S. 59-90.

Vogt, Arnold, Religion im Militär. Seelsorge zwischen Kriegsverherrlichung und Humanität. Eine militärgeschichtliche Studie (= Europäische Hochschulschriften Reihe III, Bd. 253), Frankfurt am Main / Berlin / New York 1984.

Watson, Alexander, „Morale“, in: Winter, Jay / Editorial Committee of the International Research Centre of the Historial de la Grande Guerre (Hrsg.), The Cambridge History of the First World War, Vol. 2: The State, Cambridge 2014, S. 174-195.

Watson, Alexander, Ring of Steel: Germany and Austria-Hungary in World War I, New York 2014.

Zeitschrift die 93er im Weltkrieg, Heft 36/37 vom 1.3.1936; Zit. nach: Höslinger, Lebensweg, S. 27.

Ziemann, Benjamin, Front und Heimat: ländliche Kriegserfahrungen im südlichen Bayern 1914-1923 (= Veröffentlichungen des Instituts zur Erforschung der europäischen Arbeiterbewegung, Bd. 8), Essen 1997.

\section{Internetquellen}

Grazer Volksblatt Nr. 675, 12.12.1914, S. 4. http://anno.onb.ac.at/cgi-content/anno?aid=gre $\&$ datum $=19141212 \&$ query $=\% 22$ allmer\%22\&ref=anno-search [Abruf: 10.10.2017].

Department of Historic Theology, University of Vienna, Faculty of Catholic Theology, Schenkenstraße 8-10, 1010 Vienna, Austria, e-mail: thomas.schulte-umberg@ univie.ac.at

Citation: Schulte-Umberg, Thomas: „Kriegsmoral und Konfession. Perspektiven auf die katholische Feldpastoral Österreich-Ungarns im Ersten Weltkrieg im internationalen Kontext“, in: Kallhoff, Angela / Schulte-Umberg, Thomas (eds.): Moralities of Warfare and Religion (J-RaT 2018 / 1) pp. 106-145.

Datum der Publikation: 16.07.2018 